$\mathcal{G S}_{\text {https://doi.org/10.3765/sp.10.19 }}^{\text {Semantics \& Pragmatics Volume 10, Article 19, } 2017}$

This is an EARLY ACCESS version of

Claus, Berry, A. Marlijn Meijer, Sophie Repp \& Manfred Krifka. 2017. Puzzling response particles: An experimental study on the German answering system. Semantics and Pragmatics 10(19). https://doi.org/10.3765/sp.10. 19.

This version will be replaced with the final typeset version in due course. Note that page numbers will change, so cite with caution. 


\title{
Puzzling response particles: An experimental study on the German answering system*
}

\author{
Berry Claus \\ Humboldt-Universität zu Berlin \\ Sophie Repp \\ Universität zu Köln
}

\author{
A. Marlijn Meijer \\ Universität zu Köln \\ Manfred Krifka \\ Humboldt-Universität zu Berlin
}

\begin{abstract}
This paper addresses the use and interpretation of the German response particles ja, nein, and doch. In four experiments, we collected acceptabilityjudgement data for the full paradigm of standard German particles in responses to positive and negative assertions. The experiments were designed to test the empirical validity of two recent accounts of response particles, Roelofsen \& Farkas (2015) and Krifka (2013), which view response particles as propositional anaphors. The results for responses to negative antecedents were unpredicted and inconsistent with either account. A further unexpected finding was that there was large interindividual variation in the acceptability patterns for affirming responses to negative antecedents to the extent that most speakers found ja more acceptable whereas some found nein more acceptable. We discuss possible revisions of the two accounts to model the findings, and explore in how far the findings can be accounted for in alternative, ellipsis accounts of response particles.
\end{abstract}

Keywords: response particles, polarity, negation, propositional anaphors, ellipsis

\section{Introduction}

Response particles such as English yes and no are a short and frequent means of answering polar questions and of affirming or rejecting assertions. Yet response particles are puzzling. English yes and no responses are unambiguous with positive antecedents $^{1}$, for example, assertions as in (1). A yes response affirms and a no response rejects a positive antecedent.

* Part of the present work was presented at the 19th SemDial, the 20th Amsterdam Colloquium, and the 38th Annual Conference of the German Linguistic Society (DGfS). Experiment 2 and 3 of the present paper were reported in Meijer, Claus, Repp \& Krifka 2015. We thank Elisa Stein and Katharina Vnoucek for their assistance in collecting the data. This research is supported by DFG in the priority program XPrag.de (SPP 1727).

$1 \mathrm{We}$ are using the term antecedent in the meaning of antecedent to an anaphoric expression. The antecedent is a proposition that is introduced by the assertion or question that the response particle responds to. 
A: Bill smokes.

B: (i) Yes, he does.

(ii) \#Yes, he doesn't.

(iii) \#No, he does.

(iv) No, he doesn't.

For negative ${ }^{2}$ antecedents, such as the assertion in (2), yes and no are not complementary. Both response particles can be used in affirming and in rejecting responses to negative antecedents (Ginzburg \& Sag 2000, Goodhue, Pickett \& Wagner 2013, Holmberg 2015, Kramer \& Rawlins 2011). However, the responses in (2B) may differ in their acceptability (Brasoveanu, Farkas \& Roelofsen 2013, Goodhue \& Wagner 2015, Kramer \& Rawlins 2012) and there may also be some variation between native speakers of English (Kramer \& Rawlins 2012). For example, some speakers may strongly accept an affirming response to a negative antecedent with yes, as in (2B-ii), while others may not at all accept it (Holmberg 2015).
A: Bill doesn't smoke.
B: (i) Yes, he DOES.
(ii) Yes, he doesn't.
(iii) No, he DOES.
(iv) No, he doesn't.

The present article investigates the meaning and use of response particles in German. The paper addresses the acceptability of the German response particles in discourses like (1) and (2) by experimental investigation, and discusses the theoretical implications of the findings.

Pope (1976) proposed that cross-linguistically a distinction can be made between two major answering systems, polarity-based systems and truth-based systems (also cf. Jones 1999, Kuno 1973). In polarity-based systems, the choice of response particles is determined by the polarity of the response clause. That is, a response particle signals either the positive or the negative polarity of the response clause. In truth-based systems, the decisive dimension is the validity of the antecedent. A response particle signals either the truth or the falsity of the antecedent. This distinction is intuitively appealing and continues to form the basis for current crosslinguistic investigations of response particles (e.g., Holmberg 2015). However, it is not able to explain the full range of data patterns so that different accounts are called for. Recent accounts fall into two major types: ellipsis approaches and anaphor approaches. Proponents of the ellipsis approaches view response particles as elliptical

\footnotetext{
Note that we are only discussing standard response particles like yes and no in this paper, and not responses like yeah, yup, uh-huh, or right.

2 Throughout this paper, we are using the term negative in the restricted sense of propositional negation.
} 
Puzzling response particles

constructions where a full response clause is elided under syntactic identity with the antecedent, and the response particle is the remnant in the ellipsis clause (Kramer \& Rawlins 2011, Holmberg 2013, 2015). Proponents of the anaphor approaches argue that response particles are propositional anaphors (Krifka 2013, Roelofsen $\&$ Farkas 2015). The anaphor approaches explicitly address the German response system, which is the topic of the present investigation.

The paper is structured as follows. Section 2 provides a detailed description of the German response particle system, a detailed explication of the anaphor approaches proposed by Roelofsen \& Farkas (2015) and by Krifka (2013), as well as a description of the ellipsis accounts by Kramer \& Rawlins (2011) and Holmberg (2015). Section 3 reports four experiments that were designed to evaluate the empirical validity of the two anaphor approaches and to provide the first systematic investigation of acceptability patterns for German response particles. Section 4 discusses the experimental findings with respect to all accounts discussed in Section 2 and explores possible alterations to the existing accounts. Section 5 concludes the paper.

\section{German response particles: ja, nein, and doch}

The German response particle system differs from the English one in that it is a system with three particles. Besides ja and nein, it includes the particle doch. The particles ja and nein roughly correspond to English yes and no, respectively. With positive antecedents, as in (3), the use and interpretation of $j a$ and nein is clear-cut. A response with $j a$ affirms a positive antecedent and a response with nein rejects it. For negative antecedents, as in (4), ja and nein are not complementary. Both can be used to affirm a negative antecedent (see e.g., Blühdorn 2012: 386). Doch is a specialized particle which is typically used for rejecting responses to negative antecedents. ${ }^{3}$

$$
\begin{aligned}
& \text { A: Bill raucht. ('Bill smokes.') } \\
& \text { B: (i) Ja. (= He does.) } \\
& \text { (ii) Nein. (= He doesn't.) } \\
& \text { (iii) \#Doch. }
\end{aligned}
$$

A: Bill raucht nicht. ('Bill doesn't smoke.')

B: (i) Ja. (= He doesn't.)

(ii) Nein. (= He doesn't.)

(iii) Doch. (= He does.)

3 The particle can marginally be used as a response to positive antecedents (Helbig 1988), if a corresponding negative proposition can be accommodated. However, this use of doch is restricted to rather special contexts see Karagjosova 2006 for discussion. 
Note that the pattern in (4) appears to be restricted to antecedents with widest-scope negation. For antecedents with narrow scope negation (e.g., Exactly four of Bill's friends don't smoke), the use of response particles corresponds to their use for antecedents without negation ${ }^{4}$ (as in (3)), that is, $j a$ and nein are complementary and doch is not licit.

Roelofsen \& Farkas (2015) and Krifka (2013) analyze the German response particles as anaphoric expressions which require the presence of a salient proposition in the discourse context. The approaches differ with respect to the role this salient proposition plays in the anaphoric process and with respect to the role of salience itself. For reasons that will become clear instantly, we will use the term feature model to refer to the model proposed by Roelofsen \& Farkas (2015) and the term saliency account to refer to Krifka's (2013) model.

\subsection{The feature model and its assumptions for German}

The syntactic-semantic feature model proposed by Roelofsen \& Farkas (2015) is framed in terms of inquisitive semantics, which provides a fine-grained framework to distinguish different types of polar antecedents. The model draws on Farkas \& Bruce's (2010) commitment-based discourse model and builds on the distinction between polarity-based and truth-based answering systems. It is intended as a universal account of response particles. Concretely, Roelofsen \& Farkas assume that the choice of response particles cross-linguistically depends on two types of features, with one type (absolute polarity features) encoding whether the response clause has positive or negative polarity and the other type (relative polarity features) encoding whether the response clause agrees with or reverses the antecedent with regard to content and polarity.

The features are hosted by the head of a polarity phrase, see (5). The polarity head takes a clausal argument, the prejacent, which may be partially or fully elided (in bare-particle responses). The features impose presuppositions on the prejacent with regard to feature-specific semantic values. If the prejacent satisfies the presupposition of a given feature, the corresponding semantic value is passed to the polarity-phrase node and morphological insertion rules insert the polarity particle that realizes the given features. The absolute polarity features ([+] and [-]) impose a presupposition on the polarity of the prejacent: " $[+]$ and [-] presuppose that their

4 Findings reported in Brasoveanu et al. 2013 suggest that the analogous holds for English yes and no. For antecedents with a narrow scope reading of the negation (e.g., At most six volunteers did not sign up for free housing), yes was found to be preferred over no in affirming responses. This pattern is the reverse of the pattern that was found for antecedents with sentential negation (e.g., The government representatives didn't go to the Congo) and corresponds to the use of yes and no in responses to positive antecedents. 
Puzzling response particles

prejacent expresses a proposition containing a single possibility ${ }^{5}$, which is highlighted and has positive or negative polarity, respectively" (Roelofsen \& Farkas 2015: 385). The term highlighted is adopted from Roelofsen \& van Gool 2010. A highlighted possibility is one that is particularly salient and therefore may become available for subsequent anaphoric reference. ${ }^{6}$ The relative polarity features ([AGREE] and [REVERSE]) pose a presupposition on the semantic relation between the prejacent and the antecedent: [AGREE] and [REVERSE] "presuppose that their prejacent highlights a unique possibility $\alpha$, and that the discourse context contains a unique most salient antecedent possibility $\beta$ such that $\alpha$ agrees with/reverses $\beta$, both in terms of content and in terms of polarity" (Roelofsen \& Farkas 2015: 385).

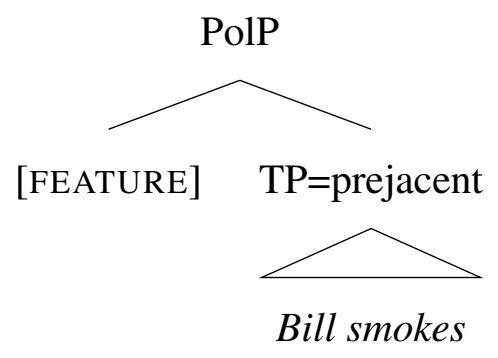

The feature-realization potentials, that is, the licit connections between features and response particles, are assumed to be language-specific. For German, Roelofsen \& Farkas propose the realization potentials in (6).

$$
\begin{aligned}
& \text { Feature realization potential of } j a, \text { nein, and doch } \\
& \text { ja can realize }[+] \text { or }[\text { AGREE] } \\
& \text { nein can realize }[-] \text { or }[\text { REVERSE] } \\
& \text { doch realizes [REVERSE, }+]
\end{aligned}
$$

With regard to the four possible feature combinations, Roelofsen \& Farkas assume the response particle assignments in (7).

$$
\begin{gathered}
\text { Feature combinations and particles in German } \\
\text { [AGREE, + ] can only be realized by ja } \\
\text { [REVERSE, - ] can only be realized by nein } \\
\text { [AGREE, - ] can be realized by ja or nein }
\end{gathered}
$$

5 The term possibility comes from inquisitive semantics, where sentences suggest possible updates of the common ground. A sentence expresses a proposition, which is a set of possibilities. A possibility is a set of indices and represents a possible update of the common ground. Simple declaratives express single possibilities, polar questions express two possibilities.

6 For instance, the polar question Is John coming? expresses the two possibilities \{John is coming, John is not coming \} and highlights the positive possibility John is coming. 
[REVERSE, +] can only be realized by doch

The proposal in (7) explains why the use of $j a$ and nein is complementary in responses to positive antecedents ([AGREE, +] and [REVERSE, - ]) and why both ja and nein can be used in affirming responses to negative antecedents ([AGREE, -]). However, the feature model implies a difference in preference between ja and nein on the basis of markedness considerations. For the absolute features, Roelofsen \& Farkas propose that $[-]$ is more marked than $[+]$, on the assumption that expressions with negative polarity are more marked than expressions with positive polarity. For the relative features, they assume that [REVERSE] is more marked than [AGREE] because the complement relation is more complex than the identity relation. Furthermore, they assume that more marked features have a higher realization need than less marked features. From these markedness considerations, predictions for preference patterns of the response particles can be derived. ${ }^{7}$ For affirming responses to negative antecedents ([AGREE, -]), the feature model predicts a preference for nein over ja because nein realizes the marked feature [-] whereas ja realizes the unmarked feature [AGREE]. For rejecting responses ([REVERSE, +]), an additional factor comes into play. Roelofsen \& Farkas assume that the particle doch is the dedicated particle for this feature combination, and therefore blocks nein and ja, that is, the feature combination [REVERSE, +] can only be realized by doch. Both markedness and the blocking mechanism are crucial in the feature model to account for the preference patterns for German response particles but note that the model in general allows for the influence of other, additional factors, for example, the pressure to avoid ambiguity (cf. Roelofsen \& Farkas 2015).

\subsection{The saliency account and its assumptions for German}

Krifka's (2013) saliency account is an optimality-theoretic approach to the interpretation of response particles. It comes with four main assumptions:

1. Response particles are propositional anaphors that pick up a propositional discourse referent (henceforth propDR), introduced by the antecedent.

2. Negative antecedents introduce two propDRs, anchored to a proposition and its negation.

3. These two propDRs differ in saliency.

4. The relative saliency of the propDRs is context-dependent.

7 Another effect of the markedness considerations is the generation of typological predictions; see Roelofsen \& Farkas 2015 for a detailed discussion. 
More specifically, Krifka analyses $j a$ as asserting the propDR it picks up whereas nein asserts the negation of the targeted propDR. This holds for positive and for negative antecedents. As already mentioned, the latter are assumed to introduce two propDRs, as illustrated in (8):

$$
\begin{aligned}
& \llbracket\left[\text { Bill }\left[\bar{p}_{D R} t_{B i l l} \text { doesn't }\left[p_{D R} t_{B i l l} \text { smoke }\right]\right]\right] \rrbracket=\neg(\operatorname{smoke}(\text { Bill })) \\
& \bar{p}_{D R}, \text { i.e., negative propDR: } \neg(\operatorname{smoke}(B i l l)) \\
& p_{D R}, \text { i.e., positive propDR: } \operatorname{smoke}(\operatorname{Bill})
\end{aligned}
$$

The negative propDR, henceforth $\bar{p}_{D R}$, is the negated proposition established by the antecedent. The positive propDR, henceforth $p_{D R}$, is the positive proposition in the scope of the negation operator. $\bar{p}_{D R}$ and $p_{D R}$ can both be picked up by anaphora (cf. ...Mary knows that $\left(\bar{p}_{D R}\right)$ vs. Mary would have known that $\left.\left(p_{D R}\right)\right)$, including the propositional anaphora ja, nein, and doch. The particle doch comes with the presupposition that both $\bar{p}_{D R}$ and $p_{D R}$ are salient and that doch picks up $p_{D R}$ and asserts it, thereby blocking $j a$ in picking up $p_{D R}$ in the context of a salient negative antecedent. This proposal, which is summarized in Table 1, results in a complementary use of $j a$ and nein with positive antecedents and a non-complementary use in affirming

\begin{tabular}{|c|c|c|c|c|}
\hline & Particle & $\begin{array}{l}\text { Targeted } \\
\text { propDR }\end{array}$ & Meaning & $\begin{array}{l}\text { Response } \\
\text { Type }\end{array}$ \\
\hline \multirow{2}{*}{$\begin{array}{l}\text { Positive } \\
\text { antecedents } \\
\text { (e.g., Bill smokes) }\end{array}$} & ja & $p_{D R}$ & $p_{D R}$ e.g, smoke(Bill) & affirmation \\
\hline & nein & $p_{D R}$ & $\neg p_{D R}$ e.g, $\neg(\operatorname{smoke}(\mathrm{Bill}))$ & rejection \\
\hline \multirow{4}{*}{$\begin{array}{l}\text { Negative } \\
\text { antecedents } \\
\text { (e.g., Bill doesn't } \\
\text { smoke) }\end{array}$} & ja & $\bar{p}_{D R}$ & $\bar{p}_{D R}$ e.g, $\neg(\operatorname{smoke}($ Bill $))$ & affirmation \\
\hline & nein & $\bar{p}_{D R}$ & $\neg \bar{p}_{D R} \quad$ e.g, smoke(Bill) & rejection \\
\hline & & $p_{D R}$ & $\neg p_{D R}$ e.g, $\neg(\operatorname{smoke}(\mathrm{Bill}))$ & affirmation \\
\hline & doch & $p_{D R}$ & $p_{D R} \quad$ e.g, smoke(Bill) & rejection \\
\hline
\end{tabular}
responses to negative antecedents, with ja picking up and asserting $\bar{p}_{D R}$, and nein picking up $p_{D R}$ and asserting its negation.

Table 1 Targeted propDR and meaning of $j a$, nein, and doch with positive and negative antecedents.

Regarding the relative saliency of $\bar{p}_{D R}$ and $p_{D R}$, Krifka proposes that $p_{D R}$ is by default more salient than $\bar{p}_{D R}$ based on the reasoning that negative antecedents are usually uttered in contexts in which the non-negated proposition is salient already. He further assumes that the relative saliencies are reversed in negative contexts, 
such as a negative question preceding the antecedent, see (9). Since more salient referents are more accessible they are more readily picked up by anaphors than less salient referents (e.g., Ariel 1990, Gundel, Hedberg \& Zacharski 1993). Therefore, the proposed relative saliencies are assumed to affect the preference patterns for $j a$ and nein.

To illustrate the predictions derivable from the saliency account, let us first consider affirming responses to negative antecedents (e.g., Bill doesn't smoke). In this case, nein picks up $p_{D R}(\operatorname{smoke}(B i l l))$ and asserts its negation, whereas ja picks up $\bar{p}_{D R}(\neg(\operatorname{smoke}(B i l l)))$ and asserts it. The preference for either of the two response particles should depend on the relative saliencies of $\bar{p}_{D R}$ and $p_{D R}$, which in turn should depend on the context. In neutral contexts (the default), $p_{D R}$ is assumed to be more salient than $\bar{p}_{D R}$, resulting in a preference for nein, which picks up $p_{D R}$. In negative contexts, this pattern should be reversed: in (9), where a negative question precedes the antecedent, $\bar{p}_{D R}$ is assumed to be more salient than $p_{D R}$, resulting in a preference for $j a$, which picks up $\bar{p}_{D R}$.
A: Wer von deinen Freunden raucht nicht? 'Which of your friends doesn't smoke?'
B: Bill raucht nicht. 'Bill doesn't smoke.'

\section{C: Ja/Nein/Doch.}

In rejecting responses to negative antecedents, nein picks up $\bar{p}_{D R}($ e.g., $\neg(\operatorname{smoke}(B i l l)))$ and asserts its negation, doch picks up $p_{D R}$ (e.g., smoke(Bill)), and asserts it, and ja (but not nein) is blocked by doch in picking up $p_{D R}$. In neutral contexts, doch, which picks up the more salient $p_{D R}$ should be preferred over nein. The reverse is predicted for negative contexts. Here nein, which picks up the more salient $\bar{p}_{D R}$, should be preferred over doch. As for ja, there should be a strong and general, viz., context-independent, dispreference.

Krifka casts this analysis in an optimality-theoretic framework. OT was originally developed to explain phenomena in phonology, and later extended to other linguistic levels. The classical architecture of an OT theory consists in the generation of different possible forms, a hierarchy of modular constraints that evaluate these forms, and an algorithm that identifies the optimal forms. OT has been employed to model the interaction of competing rules in pragmatics (cf. Blutner \& Zeevat 2004), and, most relevant for the current topic, the interpretation of anaphoric expressions. In particular, Beaver (2004) shows how well-known observations concerning anaphora resolution can be captured by a set of ranked constraints. Crucially, the underlying framework is bidirectional OT (Benz \& Mattausch 2011), which evaluates pairings of forms and meaning. This allows handling blocking phenomena, like the observation 
Puzzling response particles

that simple anaphors, like pronouns, prefer salient discourse referents, which leaves more complex forms, like stressed pronouns or full DPs, to select less salient referents (cf. Ariel 1990).

The relevant constraints for the interpretation of ja, nein and doch as anaphoric expressions that pick up propDRs are given in (10).
a. *NONSAL: Penalizes picking up a less salient discourse referent
b. PRES: Penalizes the violation of presuppositions
c. BLOCK: Meta-constraint; penalizes using non-optimal form/meaning pairs

The constraint *NONSAL is relevant for anaphora in general. It ensures that there is a preference for picking up the most salient antecedent. The notation with the asterisk means that a candidate violates the constraint if a non-salient referent is picked up. ${ }^{8}$ The constraint PRES is violated if there is a presupposition failure. ${ }^{9}$ Since the lexical entry of doch comprises the presupposition that the particle picks up $p_{D R}$ when both $\bar{p}_{D R}$ and $p_{D R}$ are present, the constraint penalizes picking up $\bar{p}_{D R}$ by doch. BLOCK is a meta-constraint by which optimal form-meaning pairs suppress the expression of the same meaning by a different form, or the use of the same form to express a different meaning (cf. Beaver 2004 on the effect of BLOCK on the use of stressed pronouns in English). In the case at hand, BLOCK has the effect that the optimal form-meaning pair $\left[\mathrm{doch} / p_{D R}\right]$ suppresses the use of $j a$, which also picks up $p_{D R}$ to express the same meaning, $p_{D R}$. The blocking of $j a$ in this case is an instance of the pragmatic rule, Maximize Presupposition (Heim 1991): doch carries a presupposition that ja doesn't. The OT tableau in Table 2 with the ranking PRES > BLOCK $>*$ NONSAL shows the resulting evaluations both in the default case when $p_{D R}$ is assumed to be more salient, and the special case when $\bar{p}_{D R}$ is more salient. With a salient $p_{D R}$, the optimal response particle is nein for affirming responses, and doch for rejecting responses to negative antecedents. With a salient $\bar{p}_{D R}, j a$ is the optimal particle for affirming, and nein for rejecting responses.

\subsection{Summary of the predictions of the feature model and saliency account}

Let us sum up and compare the predictions of the two approaches. The feature model (Roelofsen \& Farkas 2015) does not predict any context effects. For affirming

$8 *$ NONSAL is the generalization of *NEGDR, which disfavours negative discourse referents. It is proposed in Krifka 2013 as the final analysis.

9 Krifka (2013) calls the constraint *PRES. However, we think the notation without asterisk is more intuitive: the violation occurs if a presupposition is not fulfilled.

10 In the OT tableaux and some of the other tables, we use grey shading for rejections to facilitate orientation. 


\begin{tabular}{|c|c|c|c|c|c|c|}
\hline Particle & $\begin{array}{l}\text { Targeted } \\
\text { propDR }\end{array}$ & Meaning & PRES & BLOCK & *NONSAL & \\
\hline \multicolumn{7}{|c|}{ Salient propDR $=p_{D R}$} \\
\hline \multirow{2}{*}{ ja } & $p_{D R}$ & $p_{D R}=$ rejecting & & $*$ & & \\
\hline & $\bar{p}_{D R}$ & $\bar{p}_{D R}=$ affirming & & & $*$ & \\
\hline \multirow{2}{*}{ nein } & $p_{D R}$ & $\neg p_{D R}=$ affirming & & & & \& \\
\hline & $\bar{p}_{D R}$ & $\neg \bar{p}_{D R}=$ rejecting & & & $*$ & \\
\hline \multirow{2}{*}{ doch } & $p_{D R}$ & $p_{D R}=$ rejecting & & & & 0 \\
\hline & $\bar{p}_{D R}$ & $\bar{p}_{D R}=$ affirming & $*$ & & $*$ & \\
\hline \multicolumn{7}{|c|}{ Salient propDR $=\bar{p}_{D R}$} \\
\hline \multirow{2}{*}{ ja } & $p_{D R}$ & $p_{D R}=$ rejecting & & $*$ & $*$ & \\
\hline & $\bar{p}_{D R}$ & $\bar{p}_{D R}=$ affirming & & & & $\Leftrightarrow$ \\
\hline \multirow{2}{*}{ nein } & $p_{D R}$ & $\neg p_{D R}=$ affirming & & & $*$ & \\
\hline & $\bar{p}_{D R}$ & $\neg \bar{p}_{D R}=$ rejecting & & & & a \\
\hline \multirow{2}{*}{ doch } & $p_{D R}$ & $p_{D R}=$ rejecting & & & $*$ & \\
\hline & $\bar{p}_{D R}$ & $\bar{p}_{D R}=$ affirming & $*$ & & & \\
\hline
\end{tabular}

Table 2 OT tableau for $j a$, nein, and doch with negative antecedents. For rows in the same colour the meaning expressed by the particle is the same ( $p_{D R} / \neg \bar{p}_{D R}$ for rejections; $\bar{p}_{D R} / \neg p_{D R}$ for affirmations). ${ }^{10}$

responses to negative antecedents, a general preference for nein over $j a$ is predicted. For rejecting responses, there should be a strong preference for $d o c h$; both ja and nein should be strongly dispreferred and not differ in preference. The saliency account (Krifka 2013) makes the prediction that the preferences for response particles should be sensitive to the wider discourse context. For affirming responses, a preference for nein over $j a$ is predicted in default, viz., positive, contexts, whereas in negative contexts, there should be a preference for ja over nein. For rejecting responses in default contexts, there should be a preference for doch over nein, while for negative contexts a preference for nein over doch is predicted. In both contexts, $j a$ is predicted to be strongly dispreferred as a rejecting response due to the highly ranked BLOCK constraint. The preference difference between nein and $j a$ should be larger in negative contexts than in default contexts because in the former the propDR that nein picks up, 
Puzzling response particles

$\bar{p}_{D R}$, is the most salient propDR whereas in the latter it is not. Table 3 juxtaposes the predictions of the feature model and the saliency account for negative antecedents.

Response type Context

Predicted preference patterns

Saliency account Feature model

\begin{tabular}{llll}
\hline \multirow{2}{*}{ Rejecting } & Positive (default) & doch $>$ nein $>j a$ & \\
& Negative & nein $>$ doch $>j a$ & doch $>$ nein $=j a$ \\
\hline \multirow{2}{*}{ Affirming } & Positive (default) & nein $>j a$ & nein $>j a$ \\
& Negative & ja $>$ nein & \\
\hline
\end{tabular}

Table 3 Comparison of the predictions of the saliency account vs. the feature model for negative antecedents.

\subsection{The ellipsis approaches}

In the introductory section, we pointed out that there are accounts which consider bare particle answers as instances of ellipsis. Particle answers are thus subject to general syntactic licensing conditions for ellipsis. The elided constituent is the TP, the response particles occur above the TP. Ellipsis accounts have been proposed for English by Kramer \& Rawlins (2011) and for a variety of languages by Holmberg (2013, 2015). Neither of these accounts considers German in any detail. We will nevertheless describe these accounts here and propose plausible adaptations to German - on the basis of the empirical observations that the authors make for English. We will not take into consideration the empirical observations offered by Roelofsen \& Farkas (2015) and Krifka (2013) for German because - as we will see in the sections to come - these observations could not be verified by our quantitative investigations. In the general discussion, we will offer an evaluation of the ellipsis accounts and examine how they might be adapted to account for our results. ${ }^{11}$

\subsubsection{Kramer \& Rawlins (2011)}

Kramer \& Rawlins's proposal is concerned with response particles that are uttered in response to questions. We will extend their analysis to assertion-response discourses

11 Krifka (2013) and Roelofsen \& Farkas (2015) also discuss the ellipsis accounts. They highlight shortcomings that do not specifically concern the German answer system. We are restricting our exposition here to a mere description. See Section 4 for a critical evaluation. 
here because there is no principled reason not to do so (but see Section 2.4.2 for some empirical arguments against a conflation of assertions and questions as antecedents, provided by Holmberg 2015). The proposal builds on earlier work by Laka (1990) and assumes that there is a polarity phrase $\Sigma$ P above the TP. In English, $\Sigma$ may be $\varnothing$, or not or so, as in if not/so and maybe not/so. The particles yes and no adjoin to $\Sigma$ P. For German, we will assume that the response particles $j a$ and nein are $\Sigma$ heads because they may regularly occur below conditional if (wenn ja, wenn nein), which in English is not possible (*if yes, *if no) (Krifka 2013). ${ }^{12,13}$

A $\Sigma$-head may come with or without an [E]-feature, which is a feature that was proposed to be essential in the licensing of ellipsis by Merchant (2001). It occurs on the head taking the constituent that is to be elided as a complement. In the present case, this is the TP. The [E]-feature prevents the PF spellout of the $\mathrm{TP}$ and requires that the context provides an antecedent for the TP which entails and is entailed by the denotation of the TP, once focussed constituents are taken care of by F-closure (Schwarzschild 1999). In the case of response particles, the mutual entailment condition boils down to a semantic identity condition: when a bare particle is used as a response to a negative antecedent, there must be a negation in the elided TP.

Kramer \& Rawlins take the interplay of the choice of response particles and the meaning of the elided TP to be a consequence of the presence of polarity-related interpretable and uninterpretable syntactic features in the clause. The particle no has an uninterpretable negative polarity feature, uNEG; yes has no polarity feature. The uNEG feature on no forms a chain with NEG features further down in the clause. ${ }^{14}$ These may occur on the negative $\Sigma$ head and on the NegP head of clausal negation. The NEG features on $\Sigma$ and on Neg may be interpretable (iNEG) or uninterpretable (uNEG) but exactly one of them must be interpretable. The interpretable feature is the one that is lowest in the clause provided that this does not violate the semantic identity condition. Examples (11A)-(11C) are two dialogues with declarative negative antecedents that are modelled on dialogues with interrogative negative antecedents in Kramer \& Rawlins 2011. The responses in (11B)-(11C) are affirmations; (11B) uses no, (11C) uses yes. In (11B), the NEG feature on the head of the NegP inside the TP is interpretable, which conforms with the semantic identity condition: the antecedent is negative. In (11C), neither the particle, yes, nor the (nonnegative)

12 Textor (2011) argues that if yes, if no do occur in English but hints that German wenn ja, wenn nein are more frequent. We will take on a conservative stance and stick with Krifka's (2013) assumption.

13 Kramer \& Rawlins (2012) suggest that German response particles are adverbials adjoining to $\Sigma$ P but provide no arguments for this assumption.

14 The assumption that no always has an uninterpretable NEG feature which enters a chain with other, c-commanded NEG-features indicates that the denotation of no does not directly reflect its function as a polarity particle (e.g., by taking a positive proposition as argument and returning a negated one). Rather, no indicates that there is a negation lower in the clause. 
Puzzling response particles

$\Sigma$-head have polarity features. The structure and meaning of the yes-response is that of the antecedent clause and thus also conforms with the semantic identity condition.
A: Alfonso is not coming to the party.
B: No. (= He is not coming to the party.) $\left[\Sigma \mathrm{P} \mathrm{no}_{[\mathrm{uNEG}]}\left[\Sigma \mathrm{P} \Sigma_{[\mathrm{uNEG}, \mathrm{E}]}\left[\mathrm{TP}\right.\right.\right.$ he $\left[_{\mathrm{NegP}} \mathrm{Neg}_{[\mathrm{iNeG}]}[\right.$ is coming to the party]]]]]
$\mathrm{C}$ : Yes. (= He is not coming to the party.)

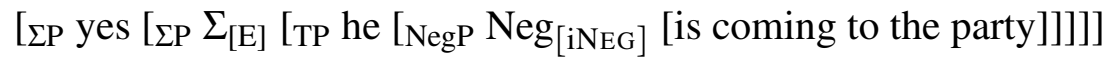

Next consider (12), a dialogue where a positive antecedent is rejected with a noresponse. In contrast to the $n o$-response in (11B), the NEG feature on the $\Sigma$ head in (12B) is interpretable because the semantic identity condition does not allow the lower NEG feature in the ellipsis site to be interpretable. Recall that the identity condition is a semantic one, not a syntactic one, so the presence of an uninterpretable negation in the elided TP does not violate the identity condition.

A: Alfonso is coming to the party.

B: No. (= He is not coming to the party.)

$\left[\Sigma \mathrm{P}\right.$ no ${ }_{[\mathrm{uNEG}}\left[\Sigma \mathrm{P} \Sigma_{[\mathrm{iNeG}, \mathrm{E}]}\left[\mathrm{TP}\right.\right.$ he $\left[_{\mathrm{NegP}} \mathrm{Neg}_{[\mathrm{uNEG}}[\right.$ is coming to the party]]]]]

Applying this system to German, we must make a few adjustments because the syntax of negation differs in English and German. We suggested above that German $j a$ and nein are probably best analysed as $\Sigma$ heads. Kramer \& Rawlins assume that $\Sigma$ heads may have an interpretable or an uninterpretable NEG feature. So we will assume for nein that it may come with an interpretable or an uninterpretable NEG feature. $J a$ has no polarity feature, just like English yes. We follow Repp (2009) in the assumption that clausal negation in German is not realized in a NegP but as a $v \mathrm{P}$ adjunct. In addition, we will assume that this adjunct may have a uNEG feature provided it can enter a chain with an iNEG feature higher up in the structure (in $\Sigma \mathrm{P}$ ), viz., in responses with response particles. (13) illustrates the syntax of affirming nein- and ja-responses to a negative antecedent. In both responses, the clausal negation has an iNEG feature. In the nein-response, the response particle has a uNEG feature and forms a chain with the iNEG feature. In the ja-response, there is no polarity feature on the $\Sigma$ head, as we mentioned above.
A: Bill raucht nicht. ('Bill does not smoke.')
B: Nein. (= 'Bill does not smoke.')

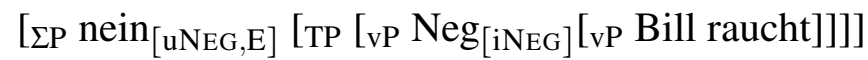
$\begin{aligned} \text { B': } & \text { Ja. (= 'Bill does not smoke.') } \\ & {\left[\Sigma \mathrm{P} \text { ja }[\text { E }]\left[\text { TP }\left[\mathrm{vP} \mathrm{Neg}_{[\mathrm{iNEG}]}[\mathrm{vP} \text { Bill raucht }]\right]\right]\right.}\end{aligned}$ 
In a rejecting response to a positive antecedent, see (14), nein must have an iNEG feature since the elided TP must not contain an interpretable negation because of the semantic identity condition.

\section{(14)}

A: Bill raucht. ('Bill smokes.')

B: Nein. (= 'Bill does not smoke.')

$\left[\Sigma \mathrm{P} \operatorname{nein}_{[\mathrm{iNEG}, \mathrm{E}]}\left[\mathrm{TP}\left[\mathrm{vP} \mathrm{Neg}_{[\mathrm{uNEG}]}[\mathrm{vP}\right.\right.\right.$ Bill raucht $\left.\left.]\right]\right]$

What we have sketched here is an analysis for a data situation, where nein and ja are equally acceptable as affirming responses to negative antecedents, which is what Kramer \& Rawlins (2011) assume for English yes and no. Kramer \& Rawlins (2011) do not provide a worked-out account for cases where a negative antecedent is rejected. In a talk handout, Kramer \& Rawlins (2012) specifically address these cases, also for languages with dedicated reversing particles, like German. For doch they suggest that the particle essentially functions like propositional negation: it takes the proposition it scopes over as its complement and reverses its truth value. The syntactic implementation makes use of an interpretable reversing feature, iREV, on doch. Another, silent instance of iREV occurs in the TP (reflecting the negative polarity of the antecedent) so that there is a REV feature chain with two interpretable instances of REV (which is not allowed for NEG features, see above). These two REV features meaning-wise cancel each other out. The result is a positive interpretation of the response, as desired.

\subsubsection{Holmberg (2015)}

Holmberg (2015) is a detailed study of answering systems in many typologically unrelated languages, which attributes the differences between answering systems on the one hand to the different syntax of the response particles themselves, and on the other hand to the availability of different syntactic positions for the negation. Furthermore, Holmberg suggests that response particles may have a different syntax and semantics in responses to questions vs. assertions. Although we are concerned with responses to assertions here, we will start our discussion of Holmberg's account with question-response discourses because the basic syntactic mechanism proposed for these may also become operative in assertion-response discourses. Furthermore, it is important to highlight that yes and no are syntactically ambiguous in this account.

The basic syntactic assumptions for response particles in answers to questions build on analyses developed in Holmberg (2013; and predecessors). They are quite similar to Kramer \& Rawlins's. Holmberg $(2013,2015)$ assumes that all sentences contain a polarity phrase whose head $(\mathrm{Pol}=\Sigma)$ takes the TP as complement (cf. Holmberg 2001, 2007). According to Holmberg (2015), the Pol head enters the derivation with an unvalued polarity feature $[ \pm \mathrm{Pol}]$. In negative assertions, the 
feature is valued [-Pol] by the head of the NegP further down in the clause. In positive assertions, Pol receives the default value [+Pol]. In polarity questions, the polarity feature is unvalued.

Response particles occur in the specifier of a higher Foc(us)P. They encode negative and positive polarity features, respectively. In answers to polarity questions, they assign a value to the unvalued polarity feature of the Pol head that is copied from the question, thus forming an operator-variable structure. Response particles are assumed to be focused because they pick out one of the two propositional (focus) alternatives that the question denotes. The general syntactic mechanism is illustrated for English no in (15), where no occurs in a negative-polar answer to a positive question. No encodes the negative polarity feature [-Pol], and assigns its value to the unvalued Pol head copied from the question.

A: Does he drink coffee?

B: No. (He doesn't drink coffee).

$$
\text { [FocP [no, -Pol] [PolP he [Pol' [does, T, -Pol] [TP [VP drink coffee]]]]] }
$$

Holmberg (2015) observes that this proposal cannot be easily transferred to responses to assertions because there are differences with respect to what constitutes a possible response to a question vs. an assertion. The differences are response-particlespecific so that yes and no must receive different analyses. For English yes, Holmberg proposes that in responses to assertions it does not encode a focused polarity feature but is similar to rejoinders like true or right in that it signals agreement with the preceding statement. Syntactically, rejoinders combine with a valued PolP, which corresponds to the antecedent and might be elided. Holmberg proposes that this analysis is not available to all speakers. Without going into the details here, he allows for the possibility that yes in responses to assertions for some speakers may have a positive polarity feature and forms a head-head relation with the PolP it combines with, so that the Pol head must be positive.

With respect to no, Holmberg assumes that it always forms a head-head relation. So if no is present, Pol must be negative. This assumption accounts for Holmberg's claim that no is not possible as a bare particle response to positive assertions ( $A$ : He drinks coffee. B: No*(, he doesn't)). In bare particle responses, the response clause is elided. Consequently, it must be identical with the antecedent, that is, have positive polarity. This results in a feature clash between no and the Pol of the elided response clause.

Holmberg (2015) does not consider specialized rejecting particles like doch. Holmberg (2013) suggests for the Swedish particle jo, which basically functions like German doch, that it reverses the value of the polarity chain. 
With respect to German, we do not have to make additional or different assumptions at this stage because the crucial syntactic and semantic building blocks - i.e., the assumption that there may be focused polarity particles in a FocP vs. rejoinders, which differ in the kind of complement they combine with (unvalued vs. valued PolP) — are the same as in English and Swedish. We will not transfer the empirical assumptions for English to German because Holmberg's observations for English are fairly complex and obviously have important consequences for the precise analysis. We will come back to Holmberg's proposal in Section 4.1.3, where we evaluate it with respect to our experimental findings. For ease of exposition and to avoid unnecessary complexity, neither Kramer \& Rawlins's (2011) account nor Holmberg's (2015) will be discussed in the experimental section. The experiments were designed to test the two accounts that make specific claims for German, viz., Roelofsen \& Farkas (2015) and Krifka (2013).

\section{Experiments}

The present study served two main goals. One goal was to experimentally compare the feature model and the saliency account. For this purpose, we focused on the collection of experimental data for responses to negative antecedents and explored the fact that the two approaches differ with regard to whether or not they assume effects of the discourse context. The second goal was to gain more general insights with regard to preference patterns of German response particles. To this end, we obtained data for the full paradigm of standard response particles in German for negative and for positive antecedents. We narrowed the study to assertions as antecedents, thereby avoiding the issue of negation ambiguity in polar questions (cf. Ladd 1981). As an indicator for the preference patterns of the response particles, we used acceptability ratings under the assumption that preference patterns can be inferred from acceptability patterns. In other words, the underlying assumption was that acceptability ratings reflect strength of preference. Thus, the predicted patterns for preference as shown in Table 3 should analogously hold for acceptability.

We conducted four experiments. Participants were presented with short dialogues, consisting of an assertion (e.g., The vet hasn't vaccinated the cats yet.) and a response to it. Each dialogue was preceded by a short scene-setting passage, which specified the dialogue's context. The participants' task was to judge the naturalness and suitability of the response in the given dialogue and context on a 7-point rating scale.

The four experiments differed in their foci of investigation. Experiment 1 examined full-clause $j a$ - and nein-responses to positive assertions. Experiment 2 investigated full-clause $j a$ - and nein-responses to negative assertions. Experiment 3 focused on affirming bare-particle $j a$ - and nein-responses to negative assertions. The 
focus of Experiment 4 was rejecting full-clause $j a$-, nein- and $d o c h$-responses to negative assertions. In all four experiments, we manipulated the dialogue's context. In Experiment 1, 2, and 4, the context was either positive, that is, assumed to be associated with a salient $p_{D R}$ (e.g., They are talking about which animals the vet has vaccinated already.) or negative, that is, assumed to be associated with a salient $\bar{p}_{D R}$ (e.g., They are talking about which animals the vet hasn't vaccinated yet.). In Experiment 3, the positive context was replaced by a neutral context (e.g., They are talking about the vet and the vaccination procedure.).

\subsection{Experiment 1: Responses to positive assertions}

Experiment 1 collected acceptability judgements for $j a$ and nein in full-clause responses to positive assertions. Here, the predictions of the feature model and the saliency account are uncontroversial. With affirming responses, there should be a strong preference for $j a$, which should be reflected in higher acceptability ratings for $j a$ compared with nein. This pattern is predicted to be reversed with rejecting responses. Neither the affirmation pattern nor the rejection pattern should be modulated by the experimental manipulation of the discourse context.

\subsubsection{Method}

Participants Forty-eight students (19 to 38 years, $M=25.31 ; 36$ female) participated in the experiment. The participants of all experiments reported in this paper were native speakers of German who were recruited from the student population of Humboldt-Universität zu Berlin. They gave informed consent for participation and received a monetary reimbursement for their participation. In Experiment 1, one additional participant was replaced because she/he was not a native speaker of German, and one other additional participant was replaced because her/his performance on the verification statements for the experimental items was not significantly better than chance.

Materials There were 48 experimental items, 16 filler items, and one practice item. Each item started with a short scene-setting passage followed by a dialogue between two interlocutors. The scene-setting passage introduced the two interlocutors and conveyed information about the dialogue's context. The dialogue comprised two turns: an assertion and a response to it. The response was composed of a response particle and a follow-up phrase, which clearly indicated whether the response was affirming or rejecting the assertion.

In all experimental items, the assertion had positive polarity (see the sample item in (16)). There were eight versions of each experimental item. The response 
particle was either ja or nein. The follow-up phrase of the response was either affirming (positive polarity) or rejecting (negative polarity). The final sentence of the scene-setting passage included an embedded question which served to convey the dialogue's context and either had positive polarity or negative polarity, intended to induce a salient $p_{D R}$ or a salient $\bar{p}_{D R}$, respectively. In half of the experimental items, the embedded question established broad VP focus for the assertion, that is, the antecedent of the response (e.g., [sown the lawn $]_{F}$ in (16)). In the other half of the experimental items, the embedded question was an object-focus question (e.g., They are talking about which animals the vet has vaccinated already/hasn't vaccinated yet. Antecedent: The vet has vaccinated [the cats] $F$ already).

Sample experimental item of Experiment 1

\section{Setting}

Ludwig und Hildegard lassen ihren großen Garten neu gestalten.

'Ludwig and Hildegard are having their large garden redesigned.'

Positive context: Sie sprechen darüber, was der Gärtner schon

they talk about.it what the gardener already gemacht hat.

done has

'They are talking about what the gardener has done already.'

Negative context: Sie sprechen darüber, was der Gärtner noch nicht they talk about.it what the gardener yet not gemacht hat.

done has

'They are talking about what the gardener hasn't done yet.'

\section{Dialogue}

Ludwig: Der Gärtner hat den Rasen schon gesät.

the gardener has the lawn already sown

'The gardener has sown the lawn already.'

Hildegard: Affirming: Ja/Nein, er hat den Rasen schon gesät. yes/no he has the lawn already sown

'Yes/No, he has sown the lawn already.'

Rejecting: Ja/Nein, er hat den Rasen noch nicht gesät. yes/no he has the lawn yet not sown 'Yes/No, he hasn't sown the lawn yet.' 
All embedded questions, assertions, and follow-up phrases of the responses were in present perfect tense and contained a temporal adverb, either schon ('already'), in clauses with positive polarity, or noch ('yet'), in clauses with negative polarity. The subject of each assertion was identical to the subject of the corresponding embedded question. It was either a single person, referred to by a proper name or a role description, or it was a group of people, referred to by a role description. All assertions had a transitive verb and a direct object. Each follow-up phrase matched its corresponding assertion, except that the subject was realized as a pronoun and that the polarity of the follow-up phrase was either identical or opposite to the polarity of the assertion, depending on the given version. The two interlocutors either were two females, or two males, or a female and a male. The gender of the asserting and the responding person was balanced across items.

The filler items all had negative assertions. Across all filler items, the polarity of the critical context information, the response particle, and the response type (affirming/rejecting) were counterbalanced.

To encourage the participants to read each item carefully, all items were followed by a verification statement. For eight items (six experimental and two filler items), the verification statement pertained to the critical context information; for the remaining items, it pertained to other information of the scene-setting passage or to the dialogue. True and false statements were equally distributed over all 64 items.

Designs and Procedure Experiment 1 employed a 2x2x2 within-subject design with the factors CONTEXT (positive/negative), RESPONSE PARTICLE (ja/nein), and RESPONSE TYPE (affirming/rejecting). Participants were randomly assigned to eight groups of six participants each, and the experimental items were assigned to eight sets of six items each. The eight conditions were allotted to sets and participant groups according to the counterbalancing schema for complex within-subject designs suggested by Pollatsek \& Well (1995: 793). Thus, each participant was presented with each item only once, in one of the eight conditions, and each participant received six items per condition. The number of items per condition for each participant $(n=$ $6)$ and the number of data points per condition for each item $(n=6)$ were the same in all four experiments. Experimental and filler items were presented to the participants in six different pseudorandomized orders.

Each item was presented on a computer screen in three parts. Participants were instructed to read each part carefully. By performing a mouse click, they proceeded to the next part, which was presented below the preceding part. Each item started with the presentation of the scene-setting passage. This was followed successively by the two parts of the dialogue, that is, the assertion and the response. Both were placed in a speech bubble, which was tagged by the name of the speaker. After reading the response, participants again had to perform a mouse click which caused 
the appearance of a 7-point rating scale. ${ }^{15}$ The participants' task was to judge the naturalness and suitability of the response in the given dialogue and context by taking into consideration the information from the scene-setting passage as well as the assertion and response. They were instructed to take the follow-up phrase of the response as indicative of the responding person's knowledge about the asserted state of affairs. After entering the judgement, the item and the rating scale disappeared from the screen and were replaced by the verification statement. Participants had to indicate whether the statement was correct or incorrect of the given item.

Participants were tested in group sessions, with two to eleven participants per session. They were seated in such a way that they could not read the information on another participant's screen. The procedure was illustrated by means of one practice trial. The experimental session lasted approximately $60 \mathrm{~min}$.

\subsubsection{Results and Discussion}

For all statistical analyses reported in this paper, numbers were assigned to the ratings, from 1 for 'very bad' to 7 for 'very good'. As the intervals between the various points on the rating scale cannot be assumed to be equal, we treated the rating data as ordinal data. All analyses reported in this paper were conducted by using cumulative link mixed models for ordinal data ( $\mathrm{R}$ package ordinal) with random intercepts for participants.

The distributions of the ratings in the eight conditions of Experiment 1 are shown in Figure 1. Table 4 shows the results of the analyses of the rating data. To summarize, the model for the full data set yielded significant interactions between RESPONSE TYPE and RESPONSE PARTICLE and between CONTEXT, RESPONSE TYPE, and RESPONSE PARTICLE. Separate analyses for subsets of the data that were conducted to examine the interactions revealed a different pattern for the two response type conditions. For rejecting responses, the ratings were significantly lower for $j a(\text { Median }=1)^{16}$ than for nein (Median $\left.=7\right)$ in both conditions of CONTEXT. For affirming responses, the ratings were significantly higher for ja (Median $=7$ ) than for nein (Median =1) in both conditions of CONTEXT.

15 The scale was a row of seven small round buttons. Only the endpoints were labelled, with sehr gut 'very good' and sehr schlecht 'very bad', respectively.

16 We use the median rather than the possibly more familiar arithmetic mean as an indication of central tendency because the mean is not an appropriate measure for ordinal data (Stevens 1946). 
Puzzling response particles

\begin{tabular}{|c|c|c|c|c|c|}
\hline & Fixed effects ${ }^{17}$ & $\beta$ & $S E$ & & \\
\hline \multirow{7}{*}{$\begin{array}{l}\text { Full } \\
\text { data set }\end{array}$} & CONTEXT & .46 & .22 & 2.08 & $*$ \\
\hline & RESPONSE TYPE & -7.22 & .28 & -25.54 & $* * *$ \\
\hline & RESPONSE PARTICLE & -7.41 & .29 & -25.60 & $* * *$ \\
\hline & CONTEXT $\times$ RESPONSE TYPE & -.32 & .30 & -1.06 & n.s. \\
\hline & CONTEXT $\times$ RESPONSE PARTICLE & -.61 & .31 & -1.95 & n.s. \\
\hline & RESPONSE TYPE $\times$ RESPONSE PARTICLE & 13.76 & .48 & 28.74 & $* * *$ \\
\hline & $\begin{array}{l}\text { CONTEXT } \times \text { RESPONSE TYPE } \times \\
\text { RESPONSE PARTICLE }\end{array}$ & 1.64 & .42 & 3.93 & $* * *$ \\
\hline \multirow{5}{*}{$\begin{array}{l}\text { Subset: } \\
\text { rejecting } \\
\text { conditions }\end{array}$} & CONTEXT & .47 & .22 & 2.09 & $*$ \\
\hline & RESPONSE PARTICLE & -7.07 & .36 & -19.90 & $* * *$ \\
\hline & CONTEXT $\times$ RESPONSE PARTICLE & -.62 & .31 & -1.99 & * \\
\hline & Subset: positive context RESPONSE PARTICLE & -8.87 & .61 & -14.54 & $* * *$ \\
\hline & Subset: negative context RESPONSE PARTICLE & -6.44 & .40 & -16.27 & $* * *$ \\
\hline \multirow{5}{*}{$\begin{array}{l}\text { Subset: } \\
\text { affirming } \\
\text { conditions }\end{array}$} & CONTEXT & .16 & .20 & .81 & n.s. \\
\hline & RESPONSE PARTICLE & 7.25 & .36 & 20.22 & $* * *$ \\
\hline & context $\times$ response particle & 1.09 & .29 & 3.85 & $* * *$ \\
\hline & Subset: positive context RESPONSE PARTICLE & 10.57 & .74 & 14.32 & $* * *$ \\
\hline & Subset: negative context RESPONSE PARTICLE & 6.99 & .43 & 16.28 & $* * *$ \\
\hline
\end{tabular}

Table 4 Cumulative link mixed model results for Experiment 1.

17 Reference levels for the fixed effects were 'negative context' (for CONTEXT), 'rejecting' (for RESPONSE TYPE), and 'nein' (for RESPONSE PARTICLE). 


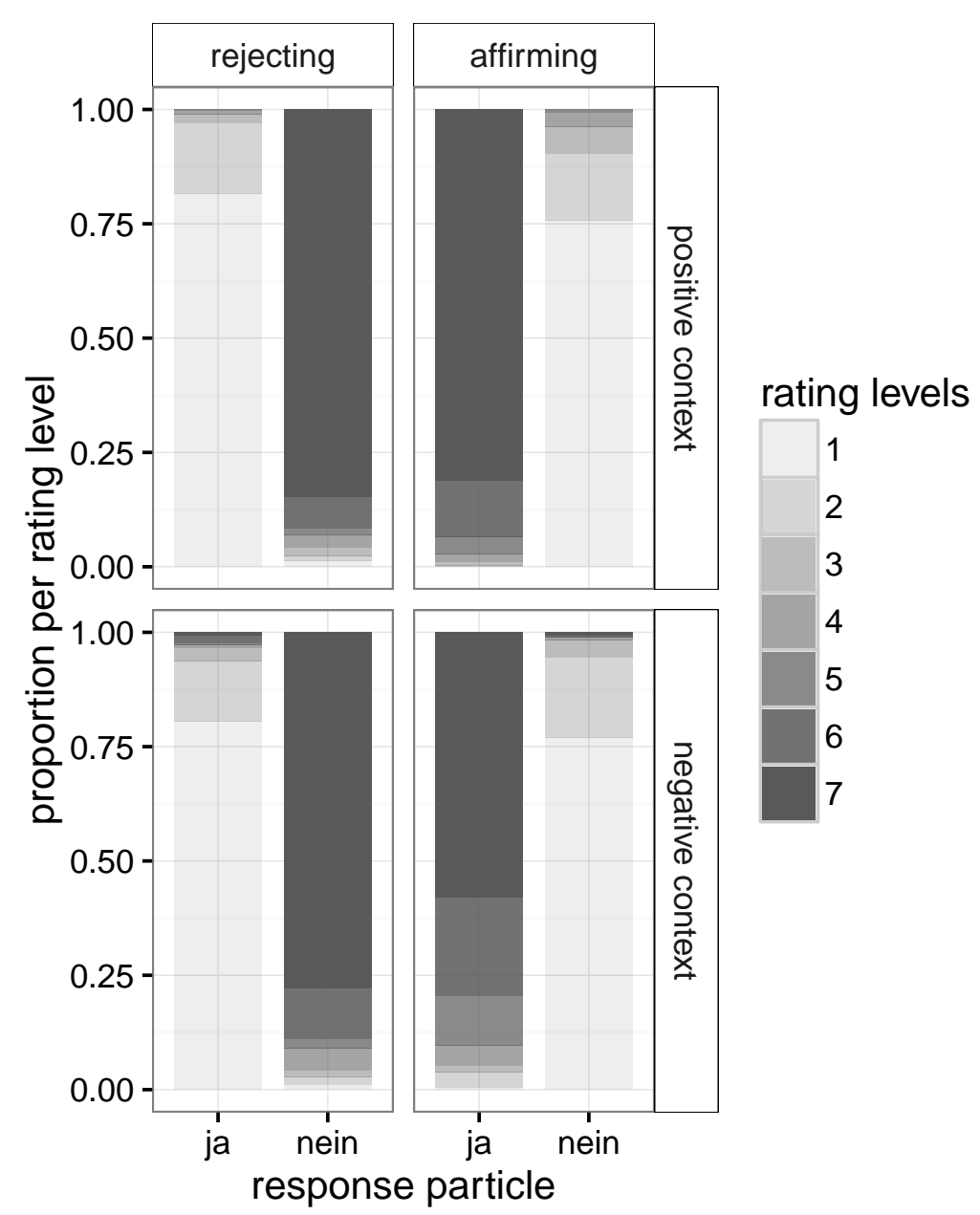

Figure 1 Proportions of the ratings per rating level, ranging from 1 ('very bad') to 7 ('very good'), in the eight conditions (CONTEXT $\times$ RESPONSE TYPE $\times$ RESPONSE PARTICLE) of Experiment 1 .

The pattern of results corroborates the uncontroversial predictions for responses to positive antecedents. It confirms the complementary use and interpretation of $j a$ and nein in affirming and rejecting responses, respectively, to positive antecedents. The effects involving the factor CONTEXT (main effects and interaction effects, see Table 4) were unexpected. Overall, the ratings for responses to positive antecedents were lower in the 'negative context' conditions than in the 'positive context' conditions, with this effect being modulated by interactions. A possible explanation of this unexpected finding may lie in superficial effects of polarity incongruity versus congruity between the context information, the antecedent assertion, and the response 
clause. For instance, after the 'negative context' sentence They are talking about what the gardener has not done yet, the positive antecedent The gardener has sown the lawn already is less coherent than it is after the 'positive context' sentence (They are talking about what the gardener has done already), which may explain the main effect of CONTEXT. This overall effect of CONTEXT may have been mitigated by the polarity of the response clause and by the response particle: the effect was most pronounced for affirming responses with $j a$, that is, when neither of the two dialogue turns nor the response particle was congruent in polarity with the negative context.

\subsection{Experiment 2: Responses to negative assertions}

Experiment 2 addressed the controversial cases of affirming and rejecting responses to negative antecedents. The method was the same as in Experiment 1 and the same materials were used, with the exception that the polarity of the antecedent assertions was reversed, that is, it was negative in all experimental items.

\subsubsection{Method}

Participants There were 48 participants (19 to 39 years, $M=25.33 ; 35$ female).

Materials The materials comprised 48 experimental items, 16 filler items, and one practice item. The items were the same as those of Experiment 1 with the following modification. In all experimental items of Experiment 2, the assertions had negative polarity (e.g., Der Gärtner hat den Rasen noch nicht gesät ('The gardener hasn't sown the lawn yet')) and in all filler items, the assertions had positive polarity. As in Experiment 1, there were eight versions of each experimental item: two versions of the dialogue's context (embedded question with positive or negative polarity), two response particles ( $j a$ or nein), and two versions of the follow-up phrase of the response (affirming or rejecting).

Design and Procedure The design of Experiment 2 was identical to that of Experiment 1, a 2x2x2 within-subject design with the factors CONTEXT (positive/negative), response particle (ja/nein), and RESPONSE TYPE (affirming/rejecting). As in Experiment 1, the eight conditions were counterbalanced across eight participant groups and eight sets of items (cf. Pollatsek \& Well 1995). The procedure was the same as in Experiment 1. 
Claus, Meijer, Repp \& Krifka

\subsubsection{Results and Discussion}

Figure 2 shows the distribution of the ratings in the eight conditions of Experiment 2. The results of cumulative link mixed models for the full data set and two subsets are given in Table 5. The analysis of the full data set revealed a significant interaction of RESPONSE TYPE with RESPONSE PARTICLE. To unpack the interactions, separate analyses for the two response-type conditions were conducted. For rejecting responses, $\mathrm{ja}$ (Median $=2$ in both context conditions) received significantly lower ratings than nein (Median $=6$ in both context conditions). For affirming responses, the ratings for $j a$ (positive context: Median =6; negative context: Median =7) were significantly higher than those for nein (Median $=5$ in both context conditions). There also was a significant interaction between CONTEXT and RESPONSE TYPE. Similar to the unexpected effects involving context that were found in Experiment 1 , this interaction may be due to effects of incongruity between the polarity of the critical context sentence, the antecedent and the response clause. The main effect of the context manipulation was significant only for affirming responses (see Table 5), that is, when neither of the two dialogue turns was congruent in polarity with the positive context.

\begin{tabular}{|c|c|c|c|c|}
\hline & Fixed effects ${ }^{18}$ & $\beta$ & $S E z$ & \\
\hline \multirow{5}{*}{ Full data set ${ }^{19}$} & CONTEXT & -.06 & $.11-.54$ & n.s. \\
\hline & RESPONSE TYPE & -.40 & $.13-3.03$ & $* *$ \\
\hline & RESPONSE PARTICLE & -3.26 & $.13-25.71$ & $* * *$ \\
\hline & CONTEXT $\times$ RESPONSE TYPE & -.38 & $.16-2.43$ & $*$ \\
\hline & $\begin{array}{l}\text { RESPONSE TYPE } \times \\
\text { RESPONSE PARTICLE }\end{array}$ & 4.76 & .1826 .80 & $* * *$ \\
\hline \multirow{2}{*}{$\begin{array}{l}\text { Subset: } \\
\text { rejecting conditions }\end{array}$} & CONTEXT & -.06 & $.11-.58$ & n.s. \\
\hline & RESPONSE PARTICLE & -3.66 & $.15-23.79$ & $* * *$ \\
\hline \multirow{2}{*}{$\begin{array}{l}\text { Subset: } \\
\text { affirming conditions }\end{array}$} & CONTEXT & -.46 & $.11-4.12$ & $* * *$ \\
\hline & RESPONSE PARTICLE & 1.65 & .1213 .63 & $* * *$ \\
\hline
\end{tabular}

Table 5 Cumulative link mixed model results for Experiment 2. 


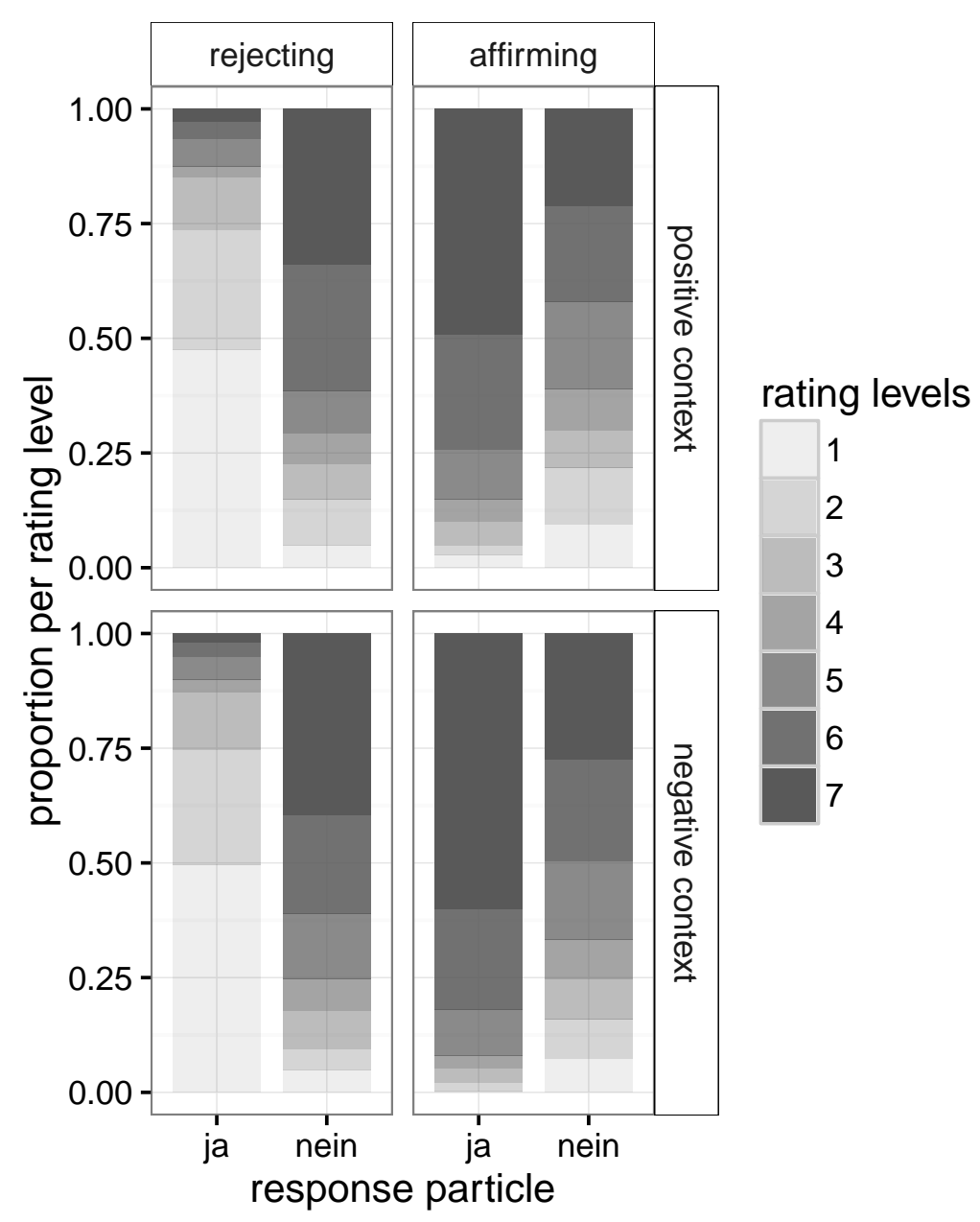

Figure 2 Proportions of the ratings per rating level, ranging from 1 ('very bad') to 7 ('very good'), in the eight conditions (CONTEXT $\times$ RESPONSE TYPE $\times$ RESPONSE PARTICLE) of Experiment 2 .

For rejecting responses, the data indicate a higher acceptability for nein than for $j a$. This finding is inconsistent with Roelofsen \& Farkas's (2015) specific assumptions for German, that is, the proposed blocking characteristic of doch, which implies that $j a$ and nein should not differ in acceptability because both are assumed to be blocked by doch. For affirming responses, the ratings indicate a higher acceptability

18 Reference levels for the fixed effects were 'negative context' (for CONTEXT), 'rejecting' (for RESPONSE TYPE), and 'nein' (for RESPONSE PARTICLE).

19 Model comparison yielded no better fit for a model including the RESPONSE PARTICLE-by-CONTEXT interaction. 
for $j a$ than for nein. This finding does not correspond to the prediction of the feature model which was derived from the proposed realization potentials for the German particles in conjunction with markedness considerations and which implies a higher acceptability for nein than for ja.

The results of Experiment 2 are also inconsistent with several predictions of the saliency account, according to which the acceptability pattern for both rejecting and affirming responses should have been affected by the context manipulation. For rejecting responses, the saliency account predicts a higher acceptability for nein than for $j a$ - which is supported by the data - with the difference being larger in the 'negative context' condition (where $\bar{p}_{D R}$, the proposition that is picked up by nein, was assumed to be salient) compared with the 'positive context' condition (where $p_{D R}$ was assumed to be salient) - which is not supported by the data. For affirming responses, the saliency account predicts a higher acceptability for nein than for ja in contexts with a salient $p_{D R}$ (neutral/positive contexts) and a higher acceptability for $j a$ than for nein in contexts with a salient $p_{D R}$ (negative contexts) - which is not confirmed by the data: $j a$ received higher acceptability ratings than nein independently of context. Thus, neither for affirming nor for rejecting responses were the acceptability patterns affected by the contextual modulation as implied by the saliency account. It is tempting to speculate that the lack of the predicted modulation by context might be due to participants not having properly attended to the critical context information. However, two pieces of evidence rule out this possibility. First, the accuracy rate for the verification statements pertaining to the context information was very high $(98 \%)$. Second, the significant interaction between CONTEXT and RESPONSE TYPE also clearly indicates that the participants paid close attention to the critical context information.

To gain a better understanding of the acceptability pattern for affirming responses in Experiment 2, which was predicted neither by the feature model nor by the saliency account, we conducted a closer inspection of the data by exploring the participants' individual acceptability patterns. We determined each participant's median ratings for affirming ja- and nein-responses as well as for rejecting ja- and nein-responses. Figure 3 shows that whereas for rejecting responses, speakers in general rated nein more acceptable than $j a$, for affirming responses there was considerable individual variation. For affirming responses, the majority of participants $(n=31)$ showed the overall pattern of a higher median rating for $j a$ than for nein. However, a large minority $(n=11)$ showed the reverse pattern, that is, a higher median rating for nein than for $j a$, and for six participants, the median ratings did not differ. Thus, the participants were not homogeneous in their acceptability patterns for affirming responses. For rejecting responses, 42 participants showed the overall pattern of higher median ratings for nein compared with ja, one participant showed the reverse pattern, and for five participants the median ratings did not differ. 


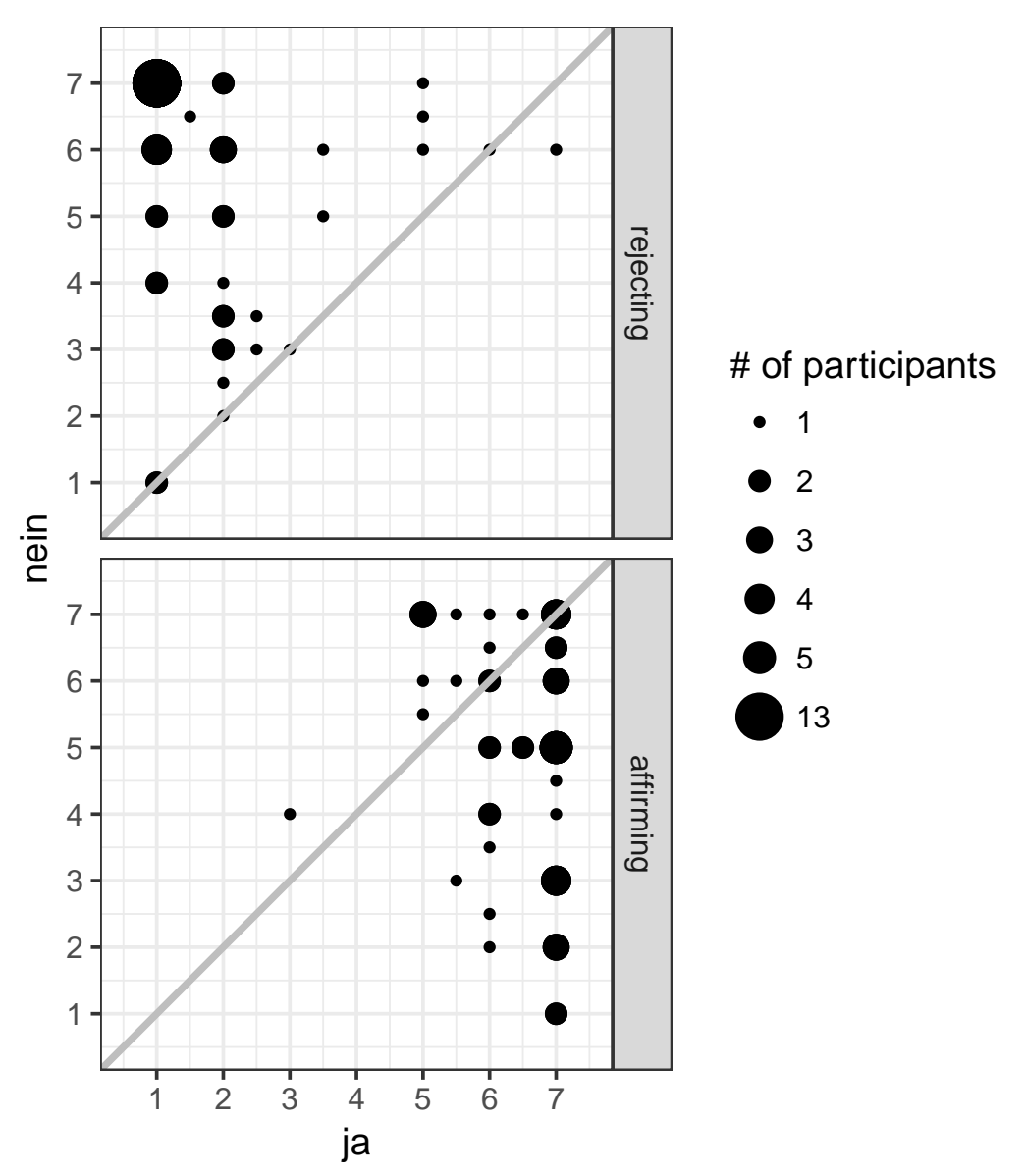

Figure 3 Experiment 2: Each participant's median rating for ja plotted against the corresponding median rating for nein. Dot size indicates the number of participants who share the given pair of median ratings. Top: rejecting responses. Bottom: affirming responses.

It is noteworthy that the interindividual variation in the acceptability patterns for affirming responses are not associated with systematic differences with regard to personal data such as region (place of birth, place where they spent most of their life), age, gender, and handedness. We will discuss possible interpretations of the individual differences in the acceptability patterns in Section 4.2.

\subsection{Experiment 3: Affirming bare-particle responses to negative assertions}

Experiment 3 investigated whether the unpredicted results obtained for affirming responses in Experiment 2 in terms of the overall pattern and the interindivid- 
ual variation could be replicated, thereby scrutinizing the role of the follow-up phrase. According to the saliency account, an affirming nein-response to a negative antecedent picks up $p_{D R}$. The follow-up phrases in the affirming conditions of Experiment 2 always were negative clauses. That is, the polarity of the follow-up phrase mismatched the polarity of the propDR assumed to be targeted by nein, but matched the polarity of the propDR assumed to be targeted by ja, viz., $\bar{p}_{D R}$. One may conjecture that the mismatch between the polarity of the follow-up phrase and the polarity of $p_{D R}$ could have reduced the ratings for nein. To explore this issue, the responses in Experiment 3 did not include a follow-up phrase but were bare particles. Information on whether a bare ja or nein should be taken as an affirming response, was provided in the scene-setting passage preceding the dialogue by a description of the epistemological state of the responding person regarding the asserted state of affairs.

A further modification of the material concerned the context manipulation and was motivated by the conjecture that the unexpected effects of context in Experiment 2 suggest that the dialogues in the 'positive context' conditions were perceived as less coherent. To avoid this issue in Experiment 3, the positive context was replaced by a neutral context, where $p_{D R}$ is assumed to be salient by default.

\subsubsection{Method}

Participants There were 24 participants (19 to 33 years, $M=23.42 ; 18$ female). The data of one additional participant were replaced because she/he had completed only less than half of the trials after 70 minutes. The data of one other additional participant were replaced because her/his performance on the verification statements of the experimental items was not significantly better than chance.

Materials There were 24 experimental items, 40 filler items, and one practice item. The items were modified versions of those of the preceding experiments. The responses were changed to bare particles. The scene-setting passages were modified such that they included information from which it was unequivocally inferable what the responding person knew about the asserted proposition (e.g., The gardener told Hildegard that he would sow the lawn in a couple of days). The positive context version was replaced by a neutral context version, where the embedded question in the final sentence of the scene-setting passage was replaced by a prepositional phrase which stated a general topic and explicitly mentioned the subject of the assertion (e.g., During lunch, Hildegard and Ludwig are talking about the gardener and the redesigning of their garden).

In all experimental items, the assertions had negative polarity and the responses were affirming, that is, the information on the responding person's knowledge state 
Puzzling response particles

was consistent with the asserted proposition. There were four versions of each experimental item: two versions of the dialogue's context (neutral/negative) and two response particles (ja/nein).

Twenty-four of the 40 filler items also had negative assertions. In all these items, the responses were rejecting, that is, the information on the epistemological state of the responding person was inconsistent with the asserted proposition. The critical context information (neutral/negative) and the response particle (ja/nein) were counterbalanced across these 24 filler items. The remaining 16 filler items had positive assertions. The six combinations of the different versions of context information, response particle, and response type (affirming/rejecting) were evenly distributed over these filler items.

In Experiment 3, the verification statements included statements pertaining to the information from the scene-setting passage on the responding person's knowledge about the asserted state of affairs (in four experimental and six filler items).

Design and Procedure Experiment 3 employed a $2 \times 2$ within-subject design with the factors CONTEXT (neutral/negative) and RESPONSE PARTICLE (ja/nein). The resulting four conditions were counterbalanced across four participant groups and four sets of items (cf. Pollatsek \& Well 1995). The same procedure as in the preceding experiments was applied with the exception that we employed a modified instruction. Participants were informed that the scene-setting passage included information as to what the responding person knows about the asserted state of affairs. They were explicitly asked to consider that information when judging the bare particle response.

\subsubsection{Result and Discussion}

Figure 4 shows the distribution of the ratings in the four conditions of Experiment 3. The cumulative link mixed model for the data of Experiment 3 included the fixed factor RESPONSE PARTICLE as the only fixed effect. ${ }^{20}$ It revealed significantly higher ratings for $j a$ (Median $=7$ in both context conditions) than for nein (Median $=4$ in both context conditions) $(\beta=1.96, S E=.17, z=11.44, p<.001)$. Thus, the results of Experiment 3 do not corroborate the suspicion that the unexpected results for the affirming conditions of Experiment 2 can be attributed to the presence of the follow-up phrase. Rather, they replicate the unpredicted finding obtained for the affirming conditions of Experiment 2 and extend it to bare particles. As in the previous experiments, there was no interaction effect between CONTEXT and RESPONSE PARTICLE. Different from the previous experiments, there was also no

20 Model comparison yielded no better fit for models including CONTEXT. The reference level for RESPONSE PARTICLE was 'nein'. 
main effect of CONTEXT. This indicates that the replacement of the positive context with a neutral context served its purpose.

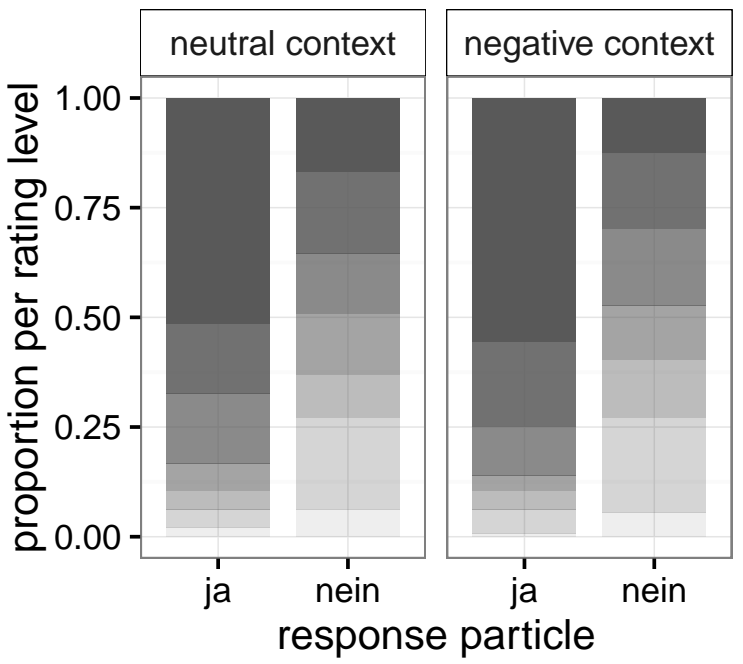

rating levels

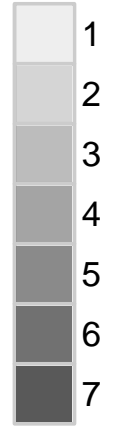

Figure 4 Proportions of the ratings per rating level, ranging from 1 ('very bad') to 7 ('very good'), in the four conditions (CONTEXT $\times$ RESPONSE PARTICLE) of Experiment 3.

As in Experiment 2, we further explored the overall result by determining each participant's median rating for $j a$ and for nein (see Figure 5). Again, the participants were heterogeneous in their acceptability patterns. The majority of the 24 participants ( $n=17$ ) showed the overall pattern of a higher median rating for $j a$ than for nein. Seven participants showed the reverse pattern, that is, a higher median rating for nein than for $j a$. Thus, the inspection of the individual acceptability patterns in Experiment 3 points in the same direction as in Experiment 2. As before, the individual differences in acceptability patterns are not associated with variables such as region, age, gender, and handedness. We will further discuss the issue of variability between participants in Section 4.2. 


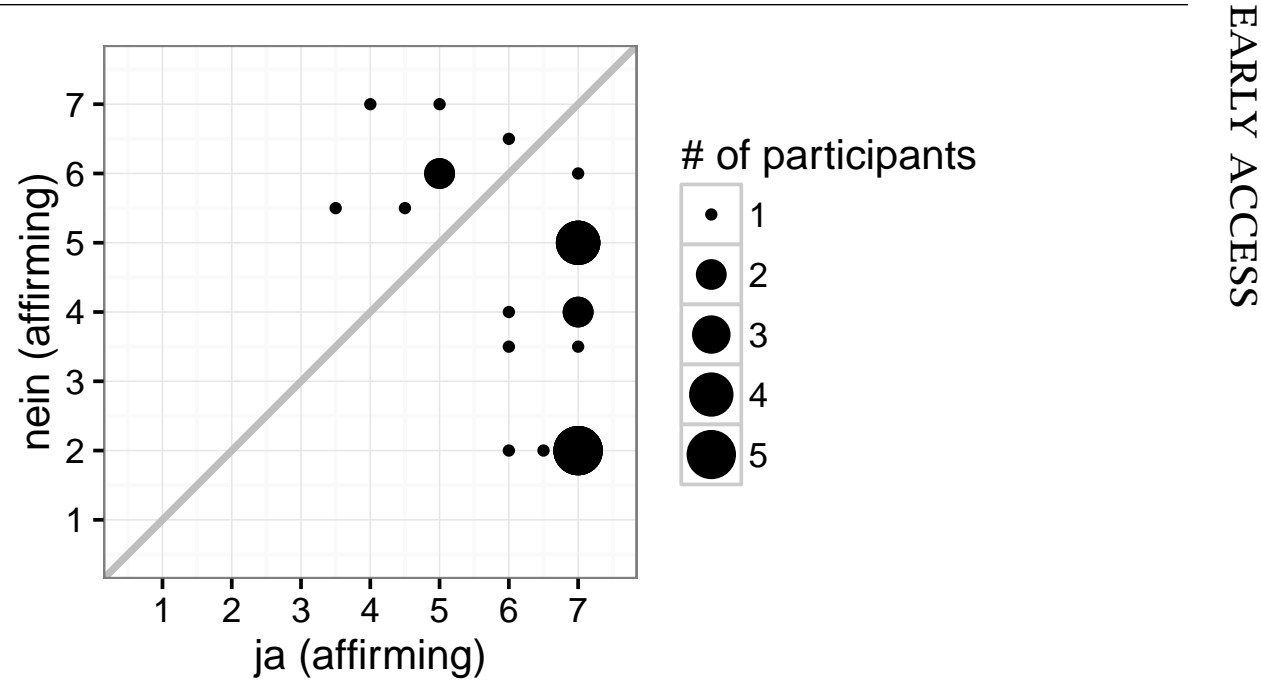

Figure 5 Experiment 3: Each participant's median rating for $j a$ as an affirming responses plotted against the corresponding median rating for nein. Dot size indicates the number of participants who share the given pair of median ratings.

\subsection{Experiment 4: Rejecting responses to negative assertions, including doch}

Experiment 4 was also a follow-up experiment of Experiment 2. It focused on rejecting responses to negative assertions and included the response particle doch, the dedicated particle for rejecting a negative antecedent, to test whether the higher acceptability of nein as compared to $j a$ that we obtained for rejecting responses in Experiment 2 might be due to the absence of the particle doch in the experimental situation. ${ }^{21}$ Therefore, the experimental items of Experiment 4 all contained rejecting responses to negative assertions, and there were three particle levels: ja, nein, and doch. In all other respects, the method was the same as in Experiment 2, including the context manipulation. That is, the context either was negative or positive (rather than neutral as in Experiment 3).

21 Note that none of the experiments offered participants a choice between particles: Participants did not choose the particle that they thought would fit best in a given context. Each dialogue contained exactly one particle answer, which participants had to rate for acceptability. So the absence of doch in Experiment 2 did not lead to participants having to make an unnatural choice. 
Claus, Meijer, Repp \& Krifka

\subsubsection{Method}

Participants There were 36 participants (19 to 36 years, $M=24.64 ; 26$ female). The data of three additional participants were replaced because their accuracy in the verification task was not significantly better than chance $(n=2)$ or because of a technical problem (computer crash; $n=1$ ).

Materials There were 36 experimental items, 28 filler items, and one practice item. The items were modified versions of those of Experiment 2. In all experimental items, the assertions had negative polarity and the responses were rejecting (i.e., followup-phrases with positive polarity). There were six versions of each experimental item: two versions of the dialogue's context, embedded question with either positive or negative polarity, and three response particles, either ja or nein or doch. Twelve of the filler items contained negative assertions. The remaining 16 filler items contained positive assertions. Across all filler items, the polarity of the critical context information, the response particle, and the response type (affirming/rejecting) were counterbalanced.

Design and Procedure Experiment 4 employed a 2x3 within-subject design with the factors CONTEXT (positive/negative) and RESPONSE PARTICLE (ja/nein/doch). The resulting six conditions were counterbalanced across six participant groups and six sets of items (cf. Pollatsek \& Well 1995). The procedure was the same as in the previous experiments.

\subsubsection{Results and Discussion}

The distribution of the ratings in the four conditions of Experiment 4 are displayed in Figure 6. The ratings were analysed with a cumulative link mixed effect model with CONTEXT and RESPONSE PARTICLE as fixed factors. ${ }^{22}$ The model yielded a significant effect of CONTEXT $(\beta=-.49, S E=.12, z=-4.07, p<.001)$, with lower ratings in the 'positive context' condition than in the 'negative context' condition. As expected, $\operatorname{doch}$ (Median $=7$ in both context conditions) received the highest ratings and $j a$ (Median = 1 in both context conditions) the lowest ratings; the ratings for nein were in between (positive context: Median = 3,5; negative context: Median =4). The ratings for doch differed significantly from the ratings for ja and nein ( $\beta=5.35, S E$ $=.24, z=22.09, p<.001)$ and the ratings for $j a$ were significantly different from the ratings for nein and doch $(\beta=-2.81, S E=.15, z=-18.17, p<.001)$. The latter

22 Model comparison yielded no better fit for a model including the RESPONSE PARTICLE-by-CONTEXT interaction. Reference levels were 'negative context' (for CONTEXT) and 'nein' (for RESPONSE PARTICLE). 
finding indicates that the finding of Experiment 2 for rejecting responses did not rest upon the absence of doch in the experimental situation. Again, the acceptability pattern was not modulated by the context manipulation. However, the main effect of context indicates that the lack of contextual modulation is not due to participants not taking into account the critical context information. With respect to individual variation, participants in Experiment 4 were quite homogeneous in rating nein more acceptable than $j a$ for rejections, just like the participants of Experiment 2 were for rejecting responses. For 30 participants, the median rating for nein was higher than that for $j a$. Two participants showed the reverse pattern, and for four participants, the median ratings did not differ between ja and nein.
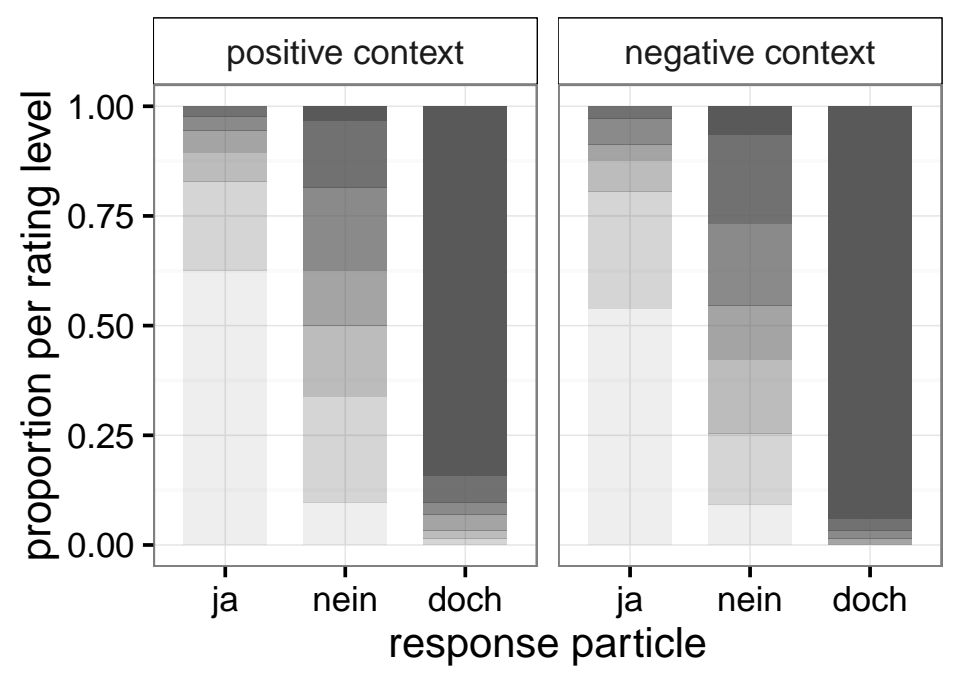

\section{rating levels}

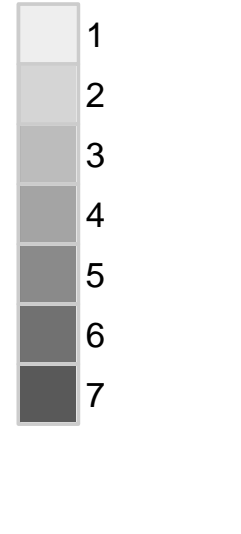

Figure 6 Proportions of the ratings per rating level, ranging from 1 ('very bad') to 7 ('very good'), in the six conditions (CONTEXT $\times$ RESPONSE PARTICLE) of Experiment 4.

\section{General Discussion}

The present study investigated acceptability patterns for German response particles with a focus on responses to negative antecedents. We considered two theoretical approaches, the feature model (Roelofsen \& Farkas 2015) and the saliency account (Krifka 2013). For responses to positive antecedents, both approaches make the same predictions: a higher acceptability for $j a$ than for nein in affirming responses, and vice versa for rejecting responses. Our rating data (Experiment 1) confirmed these generally uncontroversial predictions. Table 6 summarizes the main results in terms of median ratings for all four experiments. 
Claus, Meijer, Repp \& Krifka

\begin{tabular}{|c|c|c|c|}
\hline & Context & Rejecting & Affirming \\
\hline \multirow{2}{*}{$\begin{array}{l}\text { Positive } \\
\text { antecedent }\end{array}$} & Positive & Expt 1: ja $=1$, nein $=7$ & Expt 1: ja $=7$, nein $=1$ \\
\hline & Negative & Expt 1: ja $=1$, nein $=7$ & Expt 1: ja $=7$, nein $=1$ \\
\hline \multirow{4}{*}{$\begin{array}{l}\text { Negative } \\
\text { antecedent }\end{array}$} & Positive $^{a} /$ & Expt 2: ja $=2$, nein $=6$ & Expt 2: ja $=6$, nein $=5$ \\
\hline & Neutral $^{b}$ & Expt 4: ja $=1$, nein $=3.5$, doch $=7$ & Expt 3: ja $=7$, nein $=4$ \\
\hline & & Expt 2: ja $=2$, nein $=6$ & Expt 2: ja $=7$, nein $=5$ \\
\hline & & Expt 4: ja $=1$, nein $=4$, doch $=7$ & Expt 3: ja $=7$, nein $=4$ \\
\hline
\end{tabular}

$a$ in Expt 2 and Expt $4{ }^{b}$ in Expt 3;

Expt 1, 2, 4: particle + follow-up clause, Expt 3: bare particle

Table 6 Median ratings per condition in Experiments 1 to 4.

For responses to negative antecedents, the feature model and the saliency account make different predictions. The predictions of the feature model derive from the proposed feature realization potentials of the German particles in combination with markedness considerations, and the specific assumption for German that doch blocks both ja and nein. The predictions of the saliency account are based on the particles' proposed meanings and targeted propDRs in combination with assumptions about the relative saliency of the propDRs. Table 7 juxtaposes the predictions of the two accounts in terms of acceptability patterns for responses to negative assertions and shows the acceptability patterns obtained in Experiment 2 to 4.

For rejecting responses, the feature model predicts a high acceptability for the dedicated particle doch, which realizes the feature combination [REVERSE, +] and no difference between ja and nein, which both are assumed to be blocked by doch. The saliency account predicts that in contexts with a salient $p_{D R}$ (neutral/positive contexts) doch, which targets and asserts $p_{D R}$, is more acceptable than nein, which targets $\bar{p}_{D R}$ and asserts its negation, and nein is in turn more acceptable than $j a$, which is blocked by doch in targeting $p_{D R}$. For contexts with a salient $\bar{p}_{D R}$ (negative contexts), it predicts that nein is more acceptable than doch, which is more acceptable than ja. The difference between nein and ja should be larger in negative contexts, in which the targeted propDR of nein, $\bar{p}_{D R}$, is salient, in comparison to neutral/positive contexts. Contra the predictions of the feature model as well as the saliency account, our results for rejecting responses to negative antecedents (Experiment 2 and 4) suggest a higher acceptability for doch than for nein than for $j a$ without contextual modulation. 
Puzzling response particles

\begin{tabular}{|c|c|c|c|c|}
\hline \multirow{2}{*}{ Response type } & \multirow{2}{*}{ Context } & \multicolumn{2}{|l|}{ Predicted } & \multirow{2}{*}{$\begin{array}{l}\text { Observed } \\
\text { Expt 2-4 }\end{array}$} \\
\hline & & Saliency account & Feature model & \\
\hline Rejecting & $\begin{array}{l}\text { Positive } \\
\text { Negative }\end{array}$ & $\begin{array}{l}\text { doch }>\text { nein }>\text { ja } \\
\text { nein }>\text { doch }>\text { ja }\end{array}$ & doch $>$ nein $=j a$ & doch $>$ nein $>$ ja \\
\hline \multirow[t]{2}{*}{ Affirming } & $\begin{array}{l}\text { Positive/ } \\
\text { Neutral }\end{array}$ & $n e i n>$ ja & $n e i n>j a$ & $\begin{array}{l}\text { ja }>\text { nein } \\
\text { (majority pattern) }\end{array}$ \\
\hline & Negative & ja $>$ nein & & \\
\hline
\end{tabular}

Table 7 Comparison of the acceptability patterns for responses to negative assertions as predicted by the saliency account vs. feature model with the acceptability patterns obtained in Experiment 2 to 4.

Turning to affirming responses to negative antecedents, the feature model predicts a higher acceptability for nein, which realizes the marked feature [-], than for $j a$, which realizes the unmarked feature [AGREE]. The saliency account makes the same prediction for neutral/positive contexts, where the salient propDR is $p_{D R}$, which is picked up by nein, and predicts the reverse acceptability pattern for negative contexts, where the salient propDR is $\bar{p}_{D R}$, which is picked up by $j a$. Neither of these predictions was confirmed by the rating data obtained in the present study. The results (Experiment 2 and 3) instead point to a higher acceptability for $j a$ than for nein in affirming responses to negative antecedents without contextual modulation. It should be noted, however, that the overall median ratings for nein in affirmations of negative antecedents were fairly high (Experiment 2: Median $=5$; Experiment 3: Median =4). In view of the large interindividual variation that we observed in Experiment 2 and 3 for affirming responses to negative assertions, specifically the finding that some speakers showed a higher acceptability for nein than for ja, one might conclude that the fairly high overall median rating for nein is produced by these speakers' response. However, Figures 3 (bottom) and 5 (see Sections 3.2.2 and 3.3.2) show that even speakers that rated ja more acceptable than nein show fairly high ratings for nein.

The lack of an interaction between the context manipulation and the particle manipulation for rejecting responses on the one hand, and affirming responses on the other hand is essentially a null result, which is often delicate to interpret. Yet the lack of the predicted interaction in the present study can be considered to be both interpretable and meaningful. First, it was replicated. Second, as argued before, we can rule out that the method and materials were not sufficiently sensitive to reveal the predicted interaction. Thus, we conclude that the null result does not 
represent a failure to observe an effect but rather represents a true null effect. ${ }^{23}$ That is, our findings suggest that acceptability patterns for German particles in responses to negative antecedents are not affected by the discourse context as it was manipulated in our experimental items, that is, with a negative vs. positive question in the scene-setting passage.

To sum up, the present findings cast serious doubts on the empirical validity of both the feature model and the saliency account as applied to German, especially concerning their predictions for affirming responses to negative antecedents. However, as was reported above, a closer data inspection revealed differences between the participants in their acceptability patterns for affirming responses to negative antecedents. Not all participants showed the unexpected overall pattern. ${ }^{24}$ Some participants showed the expected pattern of a higher acceptability of nein than of ja.

In the next subsections, we will first discuss how the unpredicted overall pattern of results can be accounted for by considering possible revisions of the feature model (Section 4.1.1) and the saliency account (Section 4.1.2). In Section 4.1.3, we will discuss how the overall data pattern could be captured by the ellipsis approaches. In Section 4.2, we will explore possible interpretations of the interindividual variation in the acceptability patterns for affirming responses to negative assertions.

\subsection{Explaining the overall pattern}

\subsubsection{The feature model}

One way to account for the overall pattern in the feature model is to keep the original feature realization potentials but to assume that there is a preference for the realization of relative features. ${ }^{25}$ Thus, $j a$ preferredly realizes [AGREE] but may also realize [+], nein preferredly realizes [REVERSE] but may also realize [-]. The realization potential of the dedicated particle doch is not touched by the new preference assumption because it is 'fixed' for the feature combination [REVERSE, $+]$.

The revision of the feature model can account for the data as follows. For affirming responses to negative antecedents ([AGREE, -]), ja is the most suitable particle because it realizes the relative feature [AGREE], which is preferred. Nein is possible but dispreferred because it realizes the absolute feature [-]. Note that this is incompatible with the markedness considerations in Roelofsen \& Farkas (2015)

23 Note that a recent study by Goodhue \& Wagner (to appear) on English yes and no neither found effects of context as predicted by the saliency account.

24 Recall from Section 2.4.2 that Holmberg $(2013,2015)$ reports individual differences between speakers in English. However, he does not quantify his observations.

25 This account was proposed to us by Floris Roelofsen and Donka Farkas (p.c., December 2015). 
according to which the marked feature [-] has a higher realization need than the unmarked feature [AGREE]. So, the markedness assumptions need some adjustment in future research.

For rejecting responses to negative antecedents ([REVERSE, +]; observed acceptability pattern: doch $>$ nein $>j a$ ), doch is most acceptable because it is the dedicated particle for that feature combination. In principle, nein can also be used because it realizes [REVERSE] but, as in the original account, we assume that doch blocks nein because it realizes the more specific feature combination. Regarding the effect of blocking, we must assume that blocking does not lead to stark unacceptability but only to a dispreference because nein was found to be more acceptable than ja irrespective of the presence of doch in the experimental situation (see Table 6). We are assuming that $j a$, which may realize [+], is also blocked by doch. The lower acceptability of $j a$ in comparison to nein is due to nein realizing a relative feature, that is, a feature whose realization is preferred, and ja realizing an absolute feature. The markedness assumption in this case is not in conflict with the preference for relative features because both favour the realization of [REVERSE].

\subsubsection{The saliency account}

Before discussing a possible revision of the saliency account, let us first recall its main assumptions:

1. Response particles are propositional anaphors that pick up a propDR.

2. Negative antecedents introduce two propDRs, $\bar{p}_{D R}$ and $p_{D R}$.

3. These two propDRs differ in saliency.

4. The relative saliency of the propDRs is context-dependent.

The results of the present study are silent with regard to the first three assumptions; they can be reconciled with these assumptions but do not directly support them. However, the results are clearly inconsistent with the fourth assumption. This sets the course for revising the saliency account: the fourth assumption needs to be dismissed whereas there are no constraints with regard to the first three assumptions. In our proposed revision of the saliency account, the first two assumptions are maintained, the fourth assumption is dismissed, and the third assumption is altered. With respect to the latter, recall that Krifka (2013) proposed that of the two propDRs that a negative antecedent introduces, $p_{D R}$ is more salient than $\bar{p}_{D R}$. In our revision we will assume that $\bar{p}_{D R}$ is more salient than $p_{D R}$. The motivation for this assumption is the fact that $\bar{p}_{D R}$ is introduced by a non-embedded constituent, whereas $p_{D R}$ is

introduced by an embedded constituent. There is evidence that discourse referents 
from embedded constituents are less easily accessible, cf. Gordon, Hendrick, Ledoux \& Yang (1999) for embedded DPs, Frazier \& Clifton (2005) for embedded clauses, and Syrett \& Koev (2015) for appositives. Whether or not embedding indeed plays a role for propositions in the scope of negation needs to be explored in future research. ${ }^{26}$

We will deviate from Krifka's original proposal also in the lexical entry of doch. Specifically, we will assume that doch does not target $p_{D R}$ and assert it. Rather, the lexical entry of doch includes the presupposition that doch targets $\bar{p}_{D R}$ and asserts its negation when $\bar{p}_{D R}$ is available. The presupposition of doch is part of the conventional meaning of the particle (as in Krifka 2013), hence cannot be a conversational implicature. ${ }^{27}$

With respect to the lexical entries for ja and nein we do not deviate from Krifka (2013). As a result, doch blocks nein (rather than ja) in rejecting responses because now it is nein that picks up the same propDR as doch. Hence, in the revised version, it is nein which violates the constraint BLOCK because like its competitor doch it targets $\bar{p}_{D R}$ and BLOCK essentially ensures adherence to the principle Maximize Presupposition (see Section 2.2).

With these assumptions in place, the data pattern observed in the present study can be derived as in the OT tableau given in Table 8, where the ranking of the three constraints has been changed. ${ }^{28}$

26 Moreover, it is an open question in how far the revised assumption about the relative saliencies of $\bar{p}_{D R}$ and $p_{D R}$ may hold cross-linguistically. The present study does not allow for conclusions about other languages than German. It is thus unclear whether Krifka's original proposal for English should likewise be revised.

27 We are assuming that the presupposition of doch is similar to the presupposition of additive particles like too (cf. Kripke 2009). Similar to too, the presupposition that $\bar{p}_{D R}$ is available is difficult to accommodate (see also Footnote 3 ). Only in very specific contexts is accommodation possible, see (i)-(ii). A's remark in (i) suggests that Peter not being in Berlin is an issue, which licenses the use of doch.
(i) A: Ich glaube, Peter war gestern hier.
'I believe Peter was here yesterday.'
B: Doch, er war hier.
'Yes, he was here.'
(ii) A: Peter war gestern hier.
'Peter was here yesterday.'
B: \#Doch, er war hier.
'Yes, he was here.'

28 We are using the OT formalism as a useful tool to describe the data. The proposed ranking seems to describe the data pattern that we obtained in our experiments best. 
Puzzling response particles

\begin{tabular}{|c|c|c|c|c|c|c|}
\hline Particle & $\begin{array}{l}\text { Targeted } \\
\text { propDR }\end{array}$ & Meaning & PRES & *NONSAL & BLOCK & \\
\hline \multirow{2}{*}{ ja } & $p_{D R}$ & $p_{D R}=$ rejecting & & $*$ & & \\
\hline & $\bar{p}_{D R}$ & $\bar{p}_{D R}=$ affirming & & & & ध्र्य \\
\hline \multirow{2}{*}{ nein } & $p_{D R}$ & $\neg p_{D R}=$ affirming & & $*$ & & \\
\hline & $\bar{p}_{D R}$ & $\neg \bar{p}_{D R}=$ rejecting & & & $*$ & \\
\hline \multirow{2}{*}{ doch } & $p_{D R}$ & $\neg p_{D R}=$ affirming & $*$ & $*$ & & \\
\hline & $\bar{p}_{D R}$ & $\neg \bar{p}_{D R}=$ rejecting & & & & gy \\
\hline
\end{tabular}

Salient propDR: $\bar{p}_{D R}$

Table 8 Modified saliency account: OT tableau for ja, nein, and doch with negative antecedents.

The tableau in Table 8 shows that $j a$ is the optimal candidate for affirmations of negative antecedents because in contrast to nein, ja does not incur any constraint violations. Nein violates the constraint *NONSAL because in an affirmation it would pick up the non-salient $p_{D R}$. Doch violates the highest-ranked constraint and is predicted to be highly unacceptable, which is uncontroversial.

For rejections of negative antecedents, doch is the optimal choice. It does not incur any constraint violations. Both nein and $j a$ are non-optimal but nein violates a lower-ranked constraint and thus may be expected to be more acceptable than $j a$, which is what we found in our experimental investigations. Note that the latter assumption is only compatible with an OT formalism where non-optimal candidates can still differ in their degree of acceptability. Two variants of optimality theory that can model graded acceptability are linear optimality theory (Keller 2000) and stochastic optimality theory (Boersma \& Hayes 2001).

\subsubsection{The ellipsis approaches}

Kramer and Rawlins (2011) In Section 2.4.1, we saw that Kramer \& Rawlins (2011) assume for English that both yes and no are appropriate affirming responses to negative questions, which is a claim that for reasons of expository simplicity we extended to assertions, and to German. Our experimental results do not quite fit that claim: we found an overall higher acceptability for $j a$ than for nein. We propose to keep the analysis for $j a$ that we proposed in Section 2.4.1 (repeated in (17C)). The analysis that we proposed for nein (see (17B)) is not supported by the overall data pattern. However, the finding that nein is not totally unacceptable in affirmations is 
hard to capture in Kramer \& Rawlins' account. There is little room for 'medium' acceptability: either the grammar provides a structure or it does not. ${ }^{29}$ If the grammar provides the structure in (17B) there must be semantic or pragmatic factors that make it less suitable as an affirming response. If the grammar does not provide the structure there must be psycholinguistic repair mechanisms that lead to a medium acceptability of (17B), or there must be some alternative analysis which leads to medium acceptability.
A: Bill raucht nicht. ('Bill does not smoke.')
B: \#Nein. (= 'Bill does not smoke.')

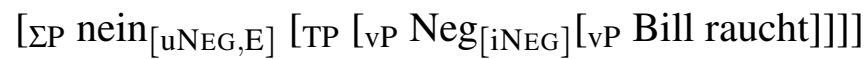
C: $\quad$ Ja. (= 'Bill does not smoke.')
$\left[\Sigma \mathrm{P} \mathrm{ja}_{[\mathrm{E}]}\left[\mathrm{TP}\left[\mathrm{vP} \mathrm{Neg}_{[\mathrm{iNEG}]}[\mathrm{vP}\right.\right.\right.$ Bill raucht $\left.\left.]\right]\right]$

Turning to rejecting responses to negative antecedents, recall that Kramer \& Rawlins (2012) propose that doch encodes an interpretable reversing feature, iREV, and that the elided TP contains another instance of iREV, see (18B). Both iREV features essentially have the semantics of clausal negation, thus producing a positive interpretation of a doch-response to a negative antecedent. Our findings generally support such an assumption for doch. The finding that nein received higher acceptability ratings than $j a$ as a rejecting response to negative antecedents can be captured by the assumption that nein always encodes an interpretable negative polarity feature, see (18C): together with the lower iNEG feature this would produce a double negation reading, creating a positive-polar, rejecting answer. Problematically, this assumption goes against one of the key assumptions in Kramer \& Rawlins (2012)'s proposal, viz., that only one NEG feature in the clause may be interpretable. One could postulate that a violation of this assumption reduces acceptability, which is why nein is less acceptable than doch in discourses like (18).

$$
\begin{aligned}
& \text { A: Bill raucht nicht. ('Bill does not smoke.') } \\
& \text { B: Doch. (= 'Bill smokes.') } \\
& {\left[\Sigma \mathrm{P} \operatorname{doch}_{[\mathrm{iRev}]}\left[\mathrm{TP} \varnothing_{[\mathrm{iRev}]}\left[{ }_{\mathrm{vP}} \mathrm{Neg}_{[\mathrm{uNEG}]}\left[{ }_{\mathrm{vP}} \text { Bill raucht }\right]\right]\right]\right.} \\
& \text { C: (\#)Nein. (= 'Bill smokes.') } \\
& {\left[\Sigma \mathrm { P } \operatorname { n e i n } _ { [ \mathrm { iNeG } , \mathrm { E } ] } \left[\mathrm{TP}\left[\mathrm{vP} \mathrm{Neg}_{[\mathrm{iNeG}]}[\mathrm{vP} \text { Bill raucht] }]\right]\right.\right.}
\end{aligned}
$$

Holmberg (2015) In Section 2.4.2, we saw that Holmberg (2015) assumes that yes-responses to an assertion usually function like the rejoinders true or right; they signal agreement with a previous utterance. However, for some speakers it might

29 There are syntax models that allow for gradience, not least OT-syntax accounts. An exploration of these is beyond the scope of this paper. 
carry a positive polarity feature, which must agree in its value with the Pol head, that is, form a head-head relation. For no, such a head-head relation always is present. We suggested that this system in principle can be carried over to German but pointed out that the empirical observations for English might not be transferable to German, which would obviously have repercussions for the precise analysis. Let us see how an analysis in Holmberg's general framework might fit the overall data pattern that we found in our experiments.

For affirming ja-responses, Holmberg's system fits very well except that the assumption of an occasional head-head relation for yes-responses to assertions cannot be transferred to German ja: ja signals agreement both after negative and after positive assertions, it always combines with a copy of the polarity-valued antecedent. Similarly to Kramer \& Rawlins's account, Holmberg's proposal faces an empirical problem with respect to the fairly high but lower-than-ja acceptability of nein in affirming responses to negative assertions. One could assume that nein optionally enters a head-head relation in such discourses and that this optionality leads to reduced acceptability. This assumption raises similar issues about graded acceptability in syntactic accounts as the one we raised in our discussion of Kramer \& Rawlins (2011).

For rejections of negative assertions, Holmberg (2013) suggested that dedicated particles like Swedish jo, and by extension German doch, reverse the value of the lower polarity chain. This fits the German data. However, the finding that nein received lower acceptability ratings than doch but higher ratings than ja in rejecting discourses is not easily explained in Holmberg's account because of the general issue with medium acceptability.

Overall, Holmberg's account allows for considerable ambiguity and a considerable number of syntactic analyses for the response particles: as focussed particles (as responses to questions), as rejoinders without head-head relation, as rejoinders with head-head relation. It does not seem to be a very parsimonious approach.

In sum, the ellipsis accounts seem to be less successful than the anaphor accounts in the explanation of the acceptability patterns that we found for the German response particles. While they can distinguish in a fairly straightforward way between 'the most acceptable' and 'the least acceptable' particle in a given dialogue, the 'in-between' findings pose problems. In the next subsection, we will address the interindividual variation that we found in affirmations to negative antecedents.

\subsection{Interindividual variation}

As was stated before, the acceptability data for affirming responses to negative assertions show substantial interindividual variation. This holds both for responses that comprise a particle and a follow-up phrase (Experiment 2) as well as for 
bare particle responses (Experiment 3). The unexpected overall data pattern that we discussed in the previous three subsections did not show for all participants. A considerable number of participants (11 of 48 in Experiment 2; 7 of 24 in Experiment 3) showed higher median ratings for nein than for ja, some participants (6 of 48 in Experiment 2; none in Experiment 3) showed no difference.

At present, the origin of the different acceptability patterns is not clear. One possibility is that they simply reflect some large variation due to random noise, viz., unsystematic variation. However, this variation-as-noise account leaves open why a large interindividual variation was only found for one particular response type: affirming responses to negative assertions. One might speculate that this response type involves particularly high processing demands, which in turn results in more noise compared with the other conditions. Yet, it is not at all evident why affirming responses to negative assertions should be associated with higher processing costs than rejecting responses. In the literature, rejecting responses to negative assertions are considered to be the most marked response type (Pope 1976, Roelofsen \& Farkas 2015). Accordingly, it is this response type that is expected to involve the highest processing demands. Moreover, the acceptability judgements of Experiment 2 and 3 exhibit a covariation between the two response types with negative antecedents. The acceptability judgements for $j a$ in affirming responses were positively correlated with those for nein in rejecting responses (Experiment 2: $r_{\tau}=.35, p<.01$; Experiment $\left.3^{30}: r_{\tau}=.63, p<.001\right)$. This finding points to a systematic covariation between the two response types, which is clearly not in line with the variation-as-noise account.

A second possibility, which was suggested to us by an anonymous reviewer, is that the interindividual variation reflects gradience in the acceptability of affirming responses to negative antecedents as a result of a property of the grammar. At first sight, this explanation seems to be consistent with the feature model and the saliency account both in their original and in their revised versions. The two accounts share the implication that in principle both $j a$ and nein can be used in affirming responses to negative antecedents, and that their acceptability should differ by degree. However, in our view the fact that a grammar predicts gradience cannot explain the observed interindividual variation. Gradience as a property of the grammar is expected to result in gradient judgements within one speaker. The judgement patterns should be the same for all speakers if they share the same grammar.

A third possibility to account for the different acceptability patterns is to assume that they actually reflect different grammars. It is possible that there are two groups of speakers that differ in the way they use response particles in affirming responses to negative antecedents. One group, the ja-group, prefers $j a$, resulting in higher acceptability ratings for $j a$ compared with nein. The other group, the nein-group,

30 Although the focus of Experiment 3 was on affirming responses to negative assertions, the filler items included conditions with rejecting responses, the data of which were used to calculate the correlation. 
has a preference for nein, resulting in higher acceptability ratings for nein than for $j a$. To be sure, the present data cannot provide direct evidence for the existence of two different groups of speakers. However, there are further arguments in favour of the assumption of two groups in addition to the finding of different acceptability patterns in Experiments 2 and 3.

First, the overall pattern of higher acceptability ratings for $j a$ than for nein, which was shown by the majority of the participants but not by all of them, was unexpected. Neither the feature model nor the saliency account, which were developed on the basis of intuitive judgements of native speakers (albeit only few), predicted it. Furthermore, highly respected 'official' descriptions of German (e.g., Dudenredaktion 2006: 603) only list nein as an affirming response to negative antecedents. It is tempting to conclude from the overall findings of the present study that these previous descriptions of the use of German response particles are simply incorrect. A more differentiated conclusion emerges when we take into account the minority pattern in the current study, that is, the higher acceptability ratings for nein compared with $j a$. The minority pattern does conform with the previous descriptions. This fact suggests that there actually exists a subgroup of speakers for which the 'official' pattern holds.

Second, there is evidence that native speakers of German, or at least some of them, are acquainted with two different usage patterns of $j a$ and nein in affirming responses to negative antecedents. Evidence for this comes from statements like "I'm at loggerheads with my students and colleagues as to how to affirm negative questions" or "A: My daughter uses ja. So far I did not try to correct her. B: Your daughter is right". Such statements can be found on web forums, where native speakers bring up the issue of two ways of expressing affirming responses to negative antecedents. ${ }^{31}$ The fact that speakers of German are aware of the two different response strategies corroborates the assumption that there are two subgroups of speakers. Moreover, this fact may also explain why for some of the participants in Experiments 2 and 3, the difference between the median ratings for ja and nein was rather small. When judging acceptability, people may take into account variation that they are accustomed to, such as different uses of response particles. Speakers who use ja to affirm a negative antecedent might still judge nein to be fairly acceptable because they know that other speakers use nein for such affirmations, and vice versa.

Third, the results of a pilot study with a different method, a production-like task, also point to the existence of two groups of speakers, a ja-group and a nein-group. Participants were presented with a set of affirming responses to a negative assertion and had to indicate which of the responses they would use themselves. The majority

31 See e.g., https://forum.wordreference.com/threads/negative-antwort-auf-negative-fragen-ein-fallder-doppelten-verneinung.1314307/, http://canoo.net/blog/2007/04/18/antwort-auf-verneintefragen/, http://www.dict.cc/forum-questions/detail-705463-Ja-Nein-Doch-Frage.html 
of participants consistently chose the ja-response and a minority consistently chose the nein-response (Frühauf, Claus, Repp, Krifka \& Meijer 2017). Thus, there is converging evidence for interindividual variation from two different methods. This points to systematic variation and lends additional credit to the assumption that the different acceptability patterns observed in Experiment 2 and 3 of the present study reflect different grammars.

We have considered three possibilities to explain the interindividual variation in the acceptability patterns for $j a$ and nein as affirmations of negative assertions. Of these three explanations the one in terms of two different speaker groups seems to be the most promising one to follow up in future research. Before concluding, we will briefly discuss how the four theoretical approaches to response particles that we discussed might capture the different grammars of the ja-group and the nein-group.

Within the feature model, the two groups could differ in the feature realization potentials or in their preferences for the realization of particular types of features. In Section 4.1.1 we discussed a possible revision of the feature model to account for the overall pattern of higher ratings for $j a$ than for nein as affirming responses to negative antecedents, viz., the pattern that corresponds to the ja-group. In the revision, we assumed a preference for the realization of relative features. In direct opposition to this assumption for the ja-group, the nein-group could be assumed to preferably realize the absolute features. As a consequence, nein would be the most suitable particle for affirming responses to negative antecedents ([AGREE,-]), because it realizes the absolute feature [-], whereas ja realizes the relative feature [AGREE].

Within the saliency account, the difference between the ja-group and the neingroup could be attributed to a difference with regard to the relative saliencies of the negative and positive propDR. To account for the overall pattern, viz. the ja-group pattern, we assumed (see Section 4.1.2), that $\bar{p}_{D R}$ is more salient than $p_{D R}$. The opposite may hold for the nein-group; $p_{D R}$ would be more salient than $\bar{p}_{D R}$. Thus, the account of the nein-group conforms to the assumptions for default contexts of the saliency account in its original version.

Turning to the ellipsis accounts, we could assume for Kramer \& Rawlins (2011) proposal that the nein-structure in (17B) above, which is not available as an affirming response to a negative assertion for the ja-group, is available for the nein-group. Conversely, the ja-group's ja-structure in (17B') is not available for the nein-group. However, the latter assumption is actually not trivial. Since ja (like yes) has no polarity feature, there is no reason why ja should not combine with a negative TP. Assuming a syntactic polarity feature for ja might be an option (cf. Holmberg 2015) but Kramer \& Rawlins do not assume that there is a positive version of NegP, with whose head ja could enter a feature chain. Also, whilst negation is well-known for inner-clausal syntactic dependencies, including concord chains, this is much less the 
case for positive polarity. Therefore, this assumption requires careful study beyond $j a$ - and nein-responses, which is a task that goes beyond the scope of the present paper.

Within Holmberg's (2015) framework, we could assume that in the nein-group, $j a$ is not a rejoinder like true or right. Rather, it has the positive polarity feature that we just discussed, which needs to enter a syntactic chain with a positive polarity head lower down in the clause. Therefore, $j a$ cannot be used as an affirming response to negative antecedents. Nein, in this group, always enters a head-head relation with the negative polarity head (which, however, requires an additional assumption for rejections, where doch is preferred over nein).

To summarize, in the feature model, the difference between the ja-group and the nein-group can be accounted for by different response strategies, in the saliency account, it is mainly attributed to negation-related processing differences, and in the ellipsis accounts it is the syntactic feature setup that makes the difference. It is plausible to assume that some of these factors have effects in domains beyond polar responses. For instance, negation-related processing differences should be detectable in the processing of negative sentences in general. Experimental investigations of this issue may help to conduct more decisive tests on the existence of two speaker groups for German ja and nein.

\section{Conclusion}

Experimental studies on the use and interpretation of response particles are sparse. The present series of experiments addressed response particles in German, which have not been quantitatively investigated so far. The findings were inconsistent with the predictions of two recent theoretical approaches to the German response particles in terms of propositional anaphora, Roelofsen \& Farkas's (2015) feature model and Krifka's (2013) saliency account. However, the unexpected results were reproducible. Hence, the present study adds to the growing body of evidence for the importance of systematic and controlled quantitative investigations.

A key finding of the current study is that there are differences between participants. On the basis of the data, we suggested that there might be two groups of speakers, who differ in their acceptability patterns for $j a$ and nein in affirming responses to negative assertions. Clearly, more, and different types of data is needed to further explore and define the existence and nature of different groups of speakers. This includes the investigation of the awareness of the different groups of speakers of each other, and the consistency of individual speakers within and across different linguistic tasks (e.g., interpretation vs. production) as well as different types of antecedents (assertions vs. questions). Furthermore, future research must include the investigation of the prosody of particle responses, which in recent studies on 
i English and Catalan has been shown to play an important role (Goodhue et al. 2013,

บy Goodhue \& Wagner 2015, González-Fuente, Tubau, Espinal \& Prieto 2015). A

$\varangle$ further highly relevant task for future research is to identify the effects of factors

$\succ$ such as negation scope and bias of polar questions (e.g., Romero \& Han 2004, Sudo

2013), the latter being an issue that we have not addressed here at all.

To account for the present findings, we discussed possible revisions of the feature model and the saliency account, as well as of ellipsis accounts. It remains an empirical task to evaluate the scope and value of these revisions. This endeavour may necessitate detailed assumptions on the processing and representation of negation as well as on the various processes involved in the choice and interpretation of response particles. It may turn out that the most valid account is one that succeeds in integrating processing insights in addition to theoretical insights from different approaches. 
Puzzling response particles

Appendix

\section{Rejecting}

\begin{tabular}{lll}
\hline Positive & $\begin{array}{l}\text { Positive } \\
\text { context }\end{array}$ & Expt 1: ja $=1.23$, nein $=6.61,95 \% \mathrm{CI}= \pm 0.23$ \\
\cline { 2 - 3 } antecedent & $\begin{array}{l}\text { Negative } \\
\text { context }\end{array}$ & Expt 1: ja $=1.35$, nein $=6.50,95 \% \mathrm{CI}= \pm 0.27$ \\
\hline Negative & Positive & Expt $2: j a=2.16$, nein $=5.24,95 \% \mathrm{CI}= \pm 0.45$ \\
antecedent & context $\quad$ Expt $4: j a=1.73$, nein $=3.66$, doch $=6.63,95 \% \mathrm{CI}= \pm 0.37$ \\
\cline { 2 - 3 } & $\begin{array}{l}\text { Negative } \\
\text { context }\end{array}$ Expt $2: j a=2.06$, nein $=5.44,95 \% \mathrm{CI}= \pm 0.42$ \\
& &
\end{tabular}

\section{Affirming}

Positive Positive Expt 1: ja $=6.70$, nein $=1.39,95 \% \mathrm{CI}= \pm 0.18$ antecedent context

Negative Expt 1: ja $=6.18$, nein $=1.33,95 \% \mathrm{CI}= \pm 0.26$ context

Negative Positive $^{a} /$ Expt 2: ja $=5.91$, nein $=4.30,95 \% \mathrm{CI}= \pm 0.43$, antecedent Neutral $^{b}$ Expt 3: ja $=5.83$, nein $=4.31,95 \% \mathrm{CI}= \pm 0.75$

Negative Expt 2: ja $=6.26$, nein $=4.96,95 \% \mathrm{CI}= \pm 0.43$, context Expt 3: ja $=5.99$, nein $=4.17,95 \% \mathrm{CI}= \pm 0.71$

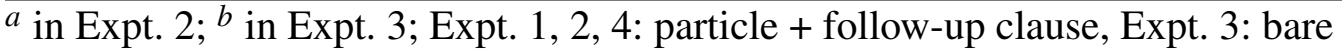
particle.

Table 9 Mean ratings per condition in Experiment 1 to 4 . The 95\%CIs are within-subject confidence intervals associated with the particle effect in the respective context and response polarity condition. ${ }^{32}$

\section{References}

Ariel, Mira. 1990. Accessing noun-phrase antecedents. London: Routledge. Beaver, David. 2004. The optimization of discourse anaphora. Linguistics and Philosophy 27. 1-53. https://doi.org/10.1023/b:ling.0000010796.76522.7a.

32 As was pointed out in Section 3.1.2 the underlying rating data are of the ordinal data type. Hence, arithmetic means and confidence intervals are incorrect measures for the present data. However, following the recommendations of the editor and one anonymous reviewer, we present these measures here for those readers who might be interested in them. 
Benz, Anton \& Jason Mattausch (eds.). 2011. Bidirectional optimality theory. Amsterdam: John Benjamins. https://doi.org/10.1075/la.180.

Blutner, Reinhard \& Henk Zeevat (eds.). 2004. Optimality theory and pragmatics. Houndmills \& New York: Palgrave McMillan. https://doi.org/10.1057/ 9780230501409.

Blühdorn, Hardarik. 2012. Negation im Deutschen [negation in German]. Tübingen: Narr Verlag.

Boersma, Paul \& Bruce Hayes. 2001. Empirical tests of the gradual learning algorithm. Linguistic Inquiry 32. 45-86. https://doi.org/10.1162/002438901554586.

Brasoveanu, Adrian, Donka Farkas \& Floris Roelofsen. 2013. N-words and sentential negation: Evidence from polarity particles and VP ellipsis. Semantics and Pragmatics 6(7). 1-33. https://doi.org/10.3765/sp.6.7.

Dudenredaktion. 2006. Duden: Die Grammatik. Mannheim: Dudenverlag 7th edn.

Farkas, Donka F. \& Kim B. Bruce. 2010. On reacting to assertions and polar questions. Journal of Semantics 27. 81-118. https://doi.org/10.1093/jos/ffp010.

Frazier, Lyn \& Charles Clifton. 2005. The syntax-discourse divide: Processing ellipsis. Syntax 8. 121-174. https://doi.org/10.1111/j.1467-9612.2005.00077.x.

Frühauf, Felix, Berry Claus, Sophie Repp, Manfred Krifka \& A. Marlijn Meijer. 2017. Two response systems for German ja and nein? Evidence from usage preference data and interpretation data. Presented at the 7th biannual Experimental Pragmatics Conference, University of Cologne.

Ginzburg, Jonathan \& Ivan A. Sag. 2000. Interrogative investigations: The form, meaning, and use of English interrogatives. Stanford, CA: CSLI Publications.

González-Fuente, Santiago, Susagna Tubau, M. Teresa Espinal \& Pilar Prieto. 2015. Is there a universal answering strategy for rejecting negative propositions? Typological evidence on the use of prosody and gesture. Frontiers in Psychology 6(899). https://doi.org/10.3389/fpsyg.2015.00899.

Goodhue, Daniel, James Pickett \& Michael Wagner. 2013. English reverse prosody in yes-no responses. In SemDial 2013 (DialDam): 17th Workshop on the Semantics and Pragmatics of Dialogue, 73-81.

Goodhue, Daniel \& Michael Wagner. 2015. It's not just what you say, it's how you say it: Intonation, yes and no. In North East Linguistics Society (NELS), vol. 45, 227-240.

Goodhue, Daniel \& Michael Wagner. to appear. Intonation, yes and no. Accepted for publication in Glossa. http://ling.auf.net/lingbuzz/003082.

Gordon, Peter C., Randall Hendrick, Kerry Ledoux \& Chin Lung Yang. 1999. Processing of reference and the structure of language: An analysis of complex noun phrases. Language and Cognitive Process 14. 353-379. https://doi.org/10. 1080/016909699386266. 
Puzzling response particles

Gundel, Jeanette K., Nancy Hedberg \& Ron Zacharski. 1993. Cognitive status and the form of referring expressions in discourse. Language 69. 274-307. https://doi.org/10.2307/416535.

Heim, Irene. 1991. Artikel und Definitheit [Articles and Definiteness]. In Armin v. Stechow \& Dieter Wunderlich (eds.), Semantik/Semantics, 487-535. Berlin: de Gruyter.

Helbig, Gerhard. 1988. Lexikon deutscher Partikeln [Dictionary of German particles]. Leipzig: Verlag Enzyklopädie.

Holmberg, Anders. 2001. The syntax of yes and no in Finnish. Studia Linguistica 55. 141-174. https://doi.org/10.1111/1467-9582.00077.

Holmberg, Anders. 2007. Null subjects and polarity focus. Studia Linguistica 61. 212-236. https://doi.org/10.1111/j.1467-9582.2007.00135.x.

Holmberg, Anders. 2013. The syntax of answers to polar questions in English and Swedish. Lingua 128. 31-50.

Holmberg, Anders. 2015. The syntax of yes and no. Oxford: Oxford University Press. https://doi.org/10.1093/acprof:oso/9780198701859.001.0001.

Jones, Bob Morris. 1999. The Welsh answering system. Berlin: de Gruyter. https: //doi.org/10.1515/9783110800593.

Karagjosova, Elena. 2006. The German response particle doch as a case of contrastive focus. In SPRIK Conference. Explicit and implicit information in text. Information structure across languages, 90-98.

Keller, Frank. 2000. Gradience in grammar. Experimental and computational aspects of degrees of grammaticality: University of Edinburgh dissertation.

Kramer, Ruth \& Kyle Rawlins. 2011. Polarity particles: an ellipsis account. In North East Linguistics Society (NELS), vol. 39, 479-491.

Kramer, Ruth \& Kyle Rawlins. 2012. An ellipsis approach to answer particles in positive and negative contexts. Paper presented at 'Workshop on the Syntax of Answers to Polar Questions', Newcastle University.

Krifka, Manfred. 2013. Response particles as propositional anaphors. In Semantics and Linguistic Theory (SALT) 23, 1-18. https://doi.org/10.3765/salt.v0i0.2676.

Kripke, Saul. 2009. Presupposition and anaphora: Remarks on the formulation of the projection problem. Linguistic Inquiry 40. 367-386. https://doi.org/10.1162/ ling.2009.40.3.367.

Kuno, Susumu. 1973. The structure of the Japanese language. Cambridge, MA: MIT Press.

Ladd, D. Robert. 1981. A first look at the semantics and pragmatics of negative questions and tag questions. In Chicago Linguistics Society, vol. 17, 164-171.

Laka, Itziar. 1990. Negation in syntax: On the nature of functional categories and projections. Cambridge: Massachusetts Institute of Technology dissertation. 
Meijer, A. Marlijn, Berry Claus, Sophie Repp \& Manfred Krifka. 2015. Particle responses to negated assertions: Preference patterns for German ja and nein. In Thomas Brochhagen, Floris Roelofsen \& Nadine Theiler (eds.), 20th Amsterdam Colloquium, 286-295.

Merchant, Jason. 2001. The syntax of silence: Sluicing, islands, and the theory of ellipsis. Oxford: Oxford University Press.

Pollatsek, Alexander \& Arnold D. Well. 1995. On the use of counterbalanced designs in cognitive research: A suggestion for a better and more powerful analysis. Journal of Experimental Psychology: Learning, Memory, and Cognition 21. 785-794.

Pope, Emily. 1976. Questions and answers in English. The Hague: Mouton.

Repp, Sophie. 2009. Negation in gapping. Oxford: Oxford University Press.

Roelofsen, Floris \& Donka Farkas. 2015. Polarity particle responses as a window onto the interpretation of questions and assertions. Language 91. 359-414. https://doi.org/10.1353/lan.2015.0017.

Roelofsen, Floris \& Sam van Gool. 2010. Disjunctive questions, intonation, and highlighting. In 17th Amsterdam Colloquium, 384-394.

Romero, Maribel \& Chung-Hye Han. 2004. On negative yes/no questions. Linguistics and Philosophy 27. 609-658. https://doi.org/10.1023/B:LING.0000033850. 15705.94.

Schwarzschild, Roger. 1999. GIVENness, AvoidF and other constraints on the placement of accent. Natural Language Semantics 7. 141-177. https://doi.org/ 10.1023/a:1008370902407.

Stevens, Stanley S. 1946. On the theory of scales of measurement. Science 103. 677-680. https://doi.org/10.1126/science.103.2684.677.

Sudo, Yasutada. 2013. Biased polar questions in English and Japanese. In Daniel Gutzmann \& Hans-Martin Gärtner (eds.), Beyond expressives: Explorations in use-conditional meaning, 277-297. Leiden: Brill. https://doi.org/10.1163/ 9789004183988_009.

Syrett, Kristen \& Todor Koev. 2015. Experimental evidence for the truth-conditional contribution and shifting information status of appositives. Journal of Semantics 32. 525-577. https://doi.org/10.1093/jos/ffu007.

Textor, Mark. 2011. Is 'no' a force-indicator? No! Analysis 71. 448-456. https: //doi.org/10.1093/analys/anr050. 
Puzzling response particles

Berry Claus

Unter den Linden 6

10099 Berlin

berry.claus@hu-berlin.de

Sophie Repp

Albertus-Magnus-Platz

50923 Köln

sophie.repp@uni-koeln.de
A. Marlijn Meijer

Albertus-Magnus-Platz

50923 Köln

a.m.meijer@uni-koeln.de

Manfred Krifka

Unter den Linden 6

10099 Berlin

krifka@hu-berlin.de 